\title{
Impact simulations on local damage of reinforced concrete panel influenced by projectile nose shape
}

\author{
Zuoyi KANG*, Akemi NISHIDA*, Yukihiko OKUDA*, Haruji TSUBOTA* and Yinsheng LI* \\ *Japan Atomic Energy Agency \\ Shirakata 2-4, Tokai-mura, Naka-gun, Ibaraki 319-1184, Japan \\ E-mail: kang.zuoyi@jaea.go.jp
}

Received: 6 November 2019; Revised: 23 December 2019; Accepted: 4 March 2020

\begin{abstract}
Most impact research has been presented on the basis of impact tests and numerical analysis performed by rigid projectile impact perpendicular to the target structure. On the other hand, there are only few reports on impacts at an oblique angle. To evaluate more realistic conditions regarding issues related to oblique impacts to reinforced concrete (RC) structures, we have proposed an analytical method to estimate the local damage to $\mathrm{RC}$ structures by oblique impact and have validated the evaluation approach by comparison with experimental results. At present, we have finalized simulation analyses of oblique impact assessments on RC panels using rigid/soft projectiles with flat nose shape utilizing the validated approach. In this study, we focus on impacts caused by rigid/soft projectiles with hemispherical nose shape. The same analytical method is applied to simulate the structural damage of the RC panel due to rigid/soft projectile with hemispherical nose shape. Results on the penetration depth of the RC structure and the energy-contribution ratio are presented. By comparing the results of local damage to RC structure caused by projectiles with flat and hemispherical nose shapes, the influence of the nose shape of projectile on local damage of $\mathrm{RC}$ panel has been investigated.
\end{abstract}

Keywords : Soft projectile, Oblique impact, Hemispherical nose shape, Reinforced concrete (RC) structure, Energy-contribution ratio

\section{Introduction}

Based on the experience from the Fukushima nuclear power plant (NPP) accident, new regulatory requirements were published by the Nuclear Regulation Authority of Japan to ensure the safety of NPPs under complex environments. The Japan Atomic Energy Agency has initiated impact analysis of the nuclear facility to enhance its structural integrity. The nuclear building has been shown to fulfill the first requirements for integrity assessments of capability against accidental impact.

Structural damage to RC structures caused by a projectile impact includes local damage and an overall dynamic elasto-plastic structural response. Impacting projectiles can be classified as either rigid or soft, depending on whether the deformability of the projectile is small or large relative to the deformability of the target structure. The deformation of the projectile is more significant than the deformation of the target structure for a soft projectile, whereas quasi-rigid projectiles primarily affect the impact zone and cause local failure of the target structure, such as cracks, penetration, and perforation. In general, the local impact effects of RC structure subjected to rigid projectile (non-deformable projectile) include penetration, cone cracking, crack formation, spalling, scabbing, and perforation.

For rigid projectile, recent empirical formula, analytical model, and numerical simulation to account for local impact effects of a hard projectile on concrete targets were discussed by Li and Reid (2005). Aspects of the penetration and scabbing limits related to rigid projectile impact were considered. Sugano et al. (1993a, 1993b) presented the results of a series of impact tests, including three sets of small, intermediate, and full-scale specimens for rigid and soft projectiles. Reduction factors to quantitatively evaluate the reduction in local damage of the test panels caused by deformable engine impact were introduced. However, the idealized analytical model is applicable only to aircraft 
engines and not to other soft projectiles. Therefore, to obtain general local damage evaluation formula for collisions of various soft projectiles, the development of local damage evaluation method based on analytical approach is necessary in addition to experimental research. As for the effect of the projectile's nose shape, specific coefficient related to the projectile's nose shape has been defined in many empirical formulas, such as the modified National Defense Research Committee (NDRC) formula (1946), the Haldar and Hamieh formula (1984), and so on. However, the definitions are limited to a few regular configurations and differ from each other. Besides, with the objective of validating the evaluation techniques applied in the assessment of the integrity of structures subjected to projectile impacts, a series of benchmark studies on impact tests to square RC panels have been reported (IRIS 2010; IRIS 2012).

It is generally accepted that the influence of normal impact to local damage of RC structure is greater than that of oblique impact. Therefore, studies on normal impacts have dominated the field of projectile impact research. However, in reality, it is possible that the approaching direction of a projectile may be restricted to an oblique direction based on the location or position of the structure of interest. For such cases, it is desirable to perform a rational evaluation that considers the influence of oblique impact. Due to the lack of oblique impact research, few experimental data associated with the local effects of oblique impacts to RC panels can be found in works (Beth and Stipe, 1943; Tanaka et al., 2004). Based on a comparison with experimental results, Ohta et al. (2017) proposed a new formula for evaluating the local damage to RC panels subjected to oblique impacts of rigid projectiles by incorporating correction effects for impact velocity, projectile diameter, slip, and rebound of the projectile into the modified NDRC formula. Also, Nishida et al. $(2017,2018,2019)$ performed simulation analyses to evaluate the perforation phenomena in RC panels subjected to the oblique impact of soft projectile by applying a validated analytical method and presented a comparison with experimental results (Koshika, 1994).

The final purpose of this study is to propose an appropriate method for evaluating the local damage to RC structure caused by oblique impact, based on past experimental results and simulations. In this paper, we consider the influence of the projectile's nose shape on the impact and simulate RC panel subjected to oblique impact of rigid and soft projectile to investigate the effect of the projectile's nose shape on the local damage to the target structure. The dynamic response characteristics and penetration mechanisms utilized in evaluating the oblique impact have been presented.

\section{Validation and analytical method}

Sugano et al. (1993a) performed a series of impact experiments on several RC panels using rigid and soft projectiles. The test apparatus and projectiles (ED: soft projectile; ER: rigid projectile) are shown in Fig. 1. A simplified 1/7.5 scale model of the GE-J79 turbojet engine installed in F-4 Phantom fighters was chosen as objective model in small-scale tests. The RC panel is a $1500 \mathrm{~mm}$ square plate with a thickness of $210 \mathrm{~mm}$. D6 and D16 deformed rebar, with nominal diameters of 6 and $16 \mathrm{~mm}$, respectively, were used for the RC panel. The soft projectile was a thin-walled cylinder with a diameter of $101 \mathrm{~mm}$ and a length of $317 \mathrm{~mm}$. The RC panel was supported at all four corners behind the panel.

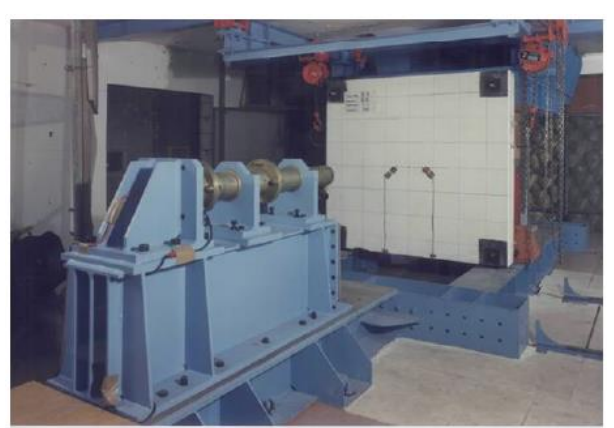

(a)

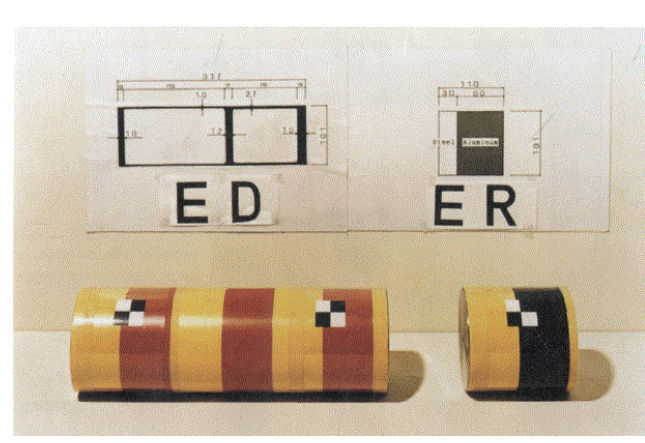

(b)

Fig. 1 (a) Setup of the impact tests and (b) impact projectiles (Sugano et al., 1993a). 
Based on our previous work (Nishida et al., 2017, 2018, 2019), the total reaction force, measured from the installed load cell on the four corner positions of the test specimen, and the panel displacement, measured by the transducer placed at the center of the rear surface (G1), were regarded as references to validate the proposed analytical approach. As can be seen in Figs. 2 and 3, both results are in satisfactory agreement and the validity of the proposed method has been confirmed.

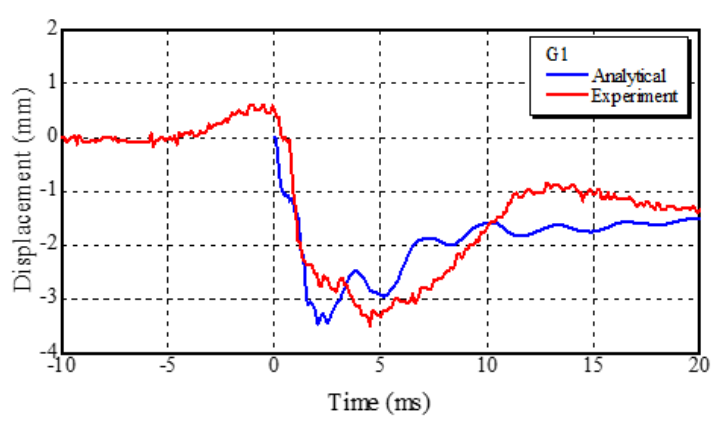

Fig. 2 Comparison of the displacement of the RC panel (Nishida et al., 2018).

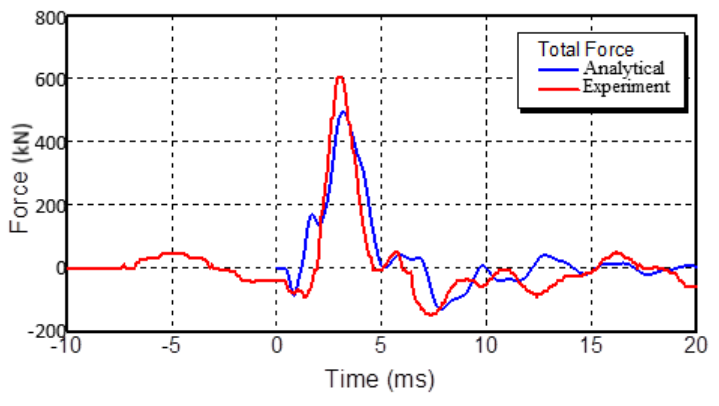

Fig. 3 Comparison of the total reaction force (Nishida et al., 2018).

Extending upon previous work, in this paper the same RC panel tested by Sugano and Tsubota (1993a) is considered as impact target, and the local damage and dynamic-impact response induced by rigid and soft projectiles with different nose shapes are simulated through applying a validated analytical method.

The finite element (FE) code LS-DYNA R7.1.2 is used to perform a numerical analysis by adopting Lagrangian FEs and explicit time integration. The code was analyzed using the supercomputer SGI ICE X at the Japan Atomic Energy Agency.

\section{Finite-element modeling}

\subsection{RC panel}

The target RC panel employed in this simulation analysis is shown in Fig. 4. The RC panel is fixed at its four corners and anchor plates are attached on both faces of the target panel. The two corresponding anchor plates are connected by 30-mm-diameter steel pipes. As described in Fig. 5, the FE model of the RC panel consists of concrete modeled by 457,464 solid elements and steel rebar modeled by 21,028 beam elements. The anchor plates and the steel pipes attached at the four corners are modeled as shell and beam elements, respectively. For the boundary conditions of the target RC panel, the steel pipe is assumed to use rigid beam element, and six degrees of freedom of the steel pipe are completely restricted. The element size of the concrete model is set to approximately $10 \mathrm{~mm}$; thus, the RC panel consists of 21 layers along the thickness direction. A single node is used to connect the solid elements of the concrete and the beam elements of the rebar, ensuring a perfect bond between the concrete and the steel-reinforcing bars.

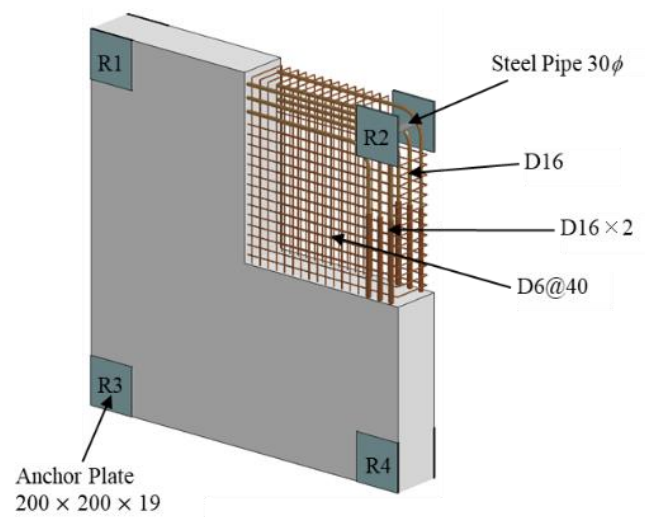

Fig. 4 Target RC panel (unit: $\mathrm{mm}$ ).

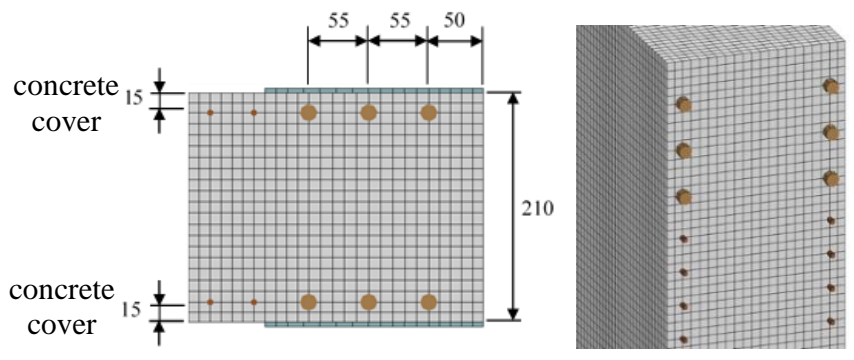

Fig. 5 Cross-section of the RC panel (unit: $\mathrm{mm}$ ). 


\subsection{Projectiles}

\subsubsection{Rigid projectiles}

Two types of rigid projectiles are modeled in this research. The front face of the projectile is designed to be hemispherical or flat, enabling an investigation of the influence of the projectile's nose shape, as shown in Fig. 6. For the front component of both rigid projectiles, the same steel material is employed, whereas the rear parts are modeled using aluminum material. Due to the differences in material density between the components of the projectile, the lengths of the front and rear components are adjusted to maintain the same mass for each projectile. All rigid projectiles are modeled using solid elements, and the same node is used to connect the steel and aluminum components of the projectiles.

In the FE formulation, we use a set of reduced integration solid elements for the concrete and rigid projectiles as well as four in-plane Gaussian point-integration beam elements for the steel rebar.
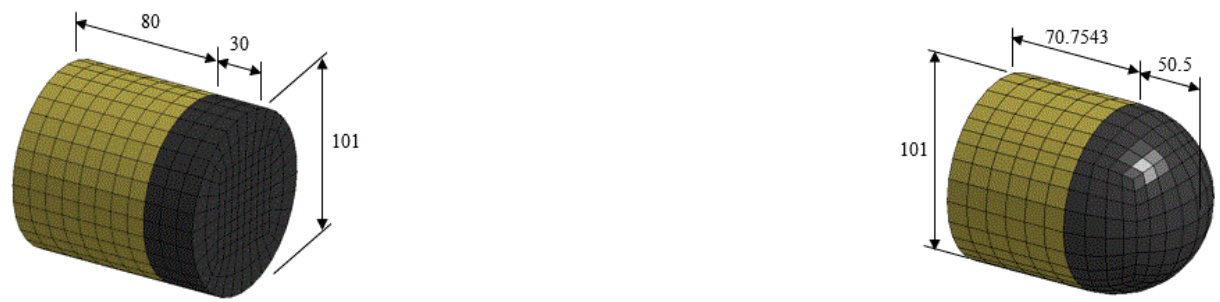

Fig. 6 FE models of rigid projectiles: flat nose shape (left) and hemispherical nose shape (right) (unit: mm).

\subsubsection{Soft projectiles}

Two types of soft projectiles with hemispherical and flat nose shapes are modeled in this research. The FE models for each type are shown in Fig. 7. The same steel material is employed for both types of soft projectiles. The two models should have the same total mass, so the thicknesses of the front nose parts of the projectiles are different. The soft projectiles are modeled using solid elements for the front nose part and rigid frame parts and shell elements for the cylindrical body part.
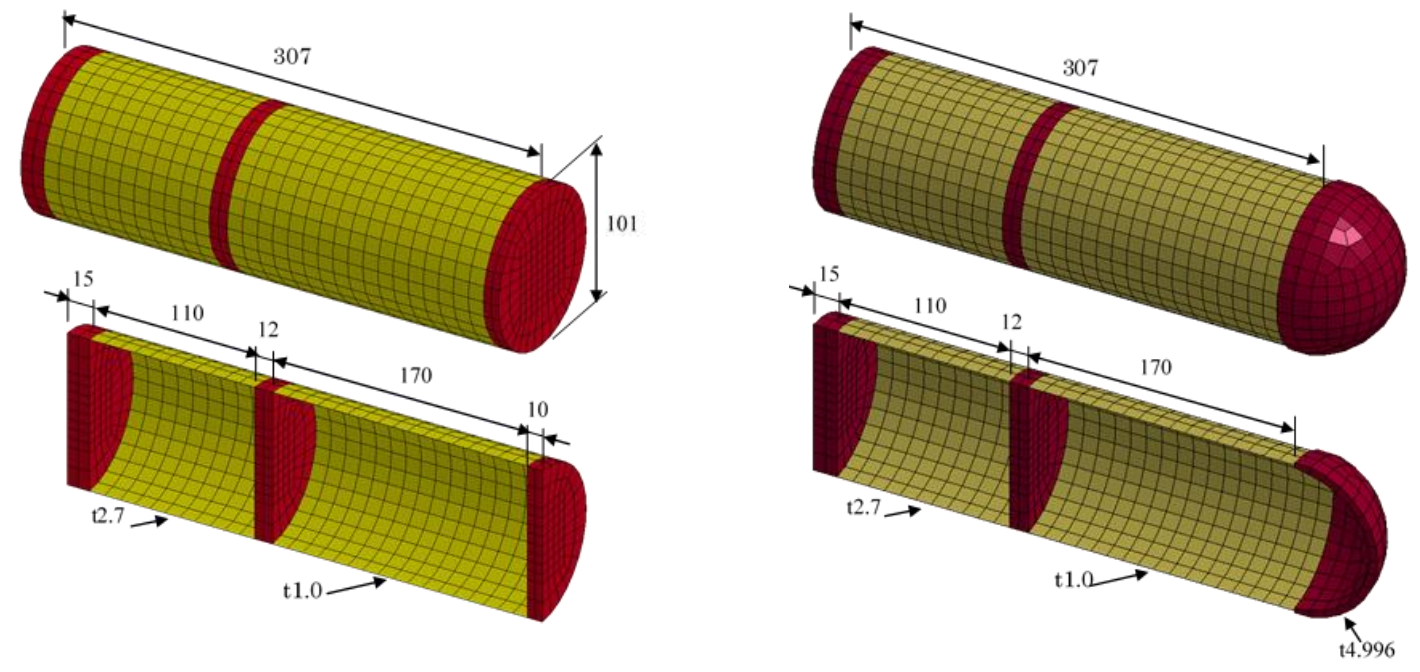

Fig. 7 FE models of soft projectiles: flat nose shape (left) and hemispherical nose shape (right) (unit: mm).

\subsection{Material properties}

It should be noted that the aforementioned small-scale tests (Sugano et al., 1993a) were conducted by the Kobori Research Complex, Tokyo, Japan. Therefore, all specimens and material were considered according to Japanese Industrial Standards (JIS) which are the standards used for industrial activities in Japan.

\subsubsection{Concrete}

The Winfrith Concrete Model (MAT084) used in this study is selected from the database of LS-DYNA. The material properties of the concrete defined in the RC panel are listed in Table 1 . In the impact analysis, the 
compressive/tensile strength and the softening curve of the concrete model after the impact may change in accordance with the strain rate dependency for each element in LS-DYNA. Since the strain rate effect of the concrete is automatically calculated in LS-DYNA, the dynamic increase factor is not applied to the compressive/tensile strength of the concrete.

Table 1 Material properties of the concrete.

\begin{tabular}{|c|c|c|}
\hline & Unit & Value \\
\hline Compressive strength & {$[\mathrm{MPa}]$} & 24.517 \\
\hline Tensile strength & {$[\mathrm{MPa}]$} & 2.746 \\
\hline Young's modulus & {$[\mathrm{MPa}]$} & 22,831 \\
\hline Poisson's ratio & & 0.2 \\
\hline Aggregate size & {$[\mathrm{mm}]$} & 10 \\
\hline Fracture shear strain & {$[\mathrm{mm} / \mathrm{mm}]$} & 0.04 \\
\hline
\end{tabular}

\subsubsection{Steel rebar}

The material properties are listed in Table 2. The true stress-true strain relationship of the steel rebar is defined using an exponential function that passes the yield stress and maximum-strength points, as illustrated in Fig. 8. The strain rate effect is considered for the steel rebar by applying the Welding Engineering Standard (WES) formula defined in WES-2808 (JWES, 2003).

Table 2 Material properties of the rebar.

\begin{tabular}{|c|c|c|c|}
\hline \multicolumn{1}{|c|}{ Table 2 Material properties of the rebar. } \\
\hline Young's modulus & Unit & D6 & D16 \\
\hline Yield stress & {$[\mathrm{MPa}]$} & 205,000 & 223,000 \\
\hline Nominal tensile strength & {$[\mathrm{MPa}]$} & 447.2 & 464.8 \\
\hline True tensile strength & {$[\mathrm{MPa}]$} & 585.5 & 653.1 \\
\hline True fracture strain & {$[\mathrm{mm} / \mathrm{mm}]$} & 685 & 764.2 \\
\hline Fracture strain & {$[\mathrm{mm} / \mathrm{mm}]$} & 0.157 & 0.157 \\
\hline Poisson's ratio & & 0.2 & 0.2 \\
\hline
\end{tabular}

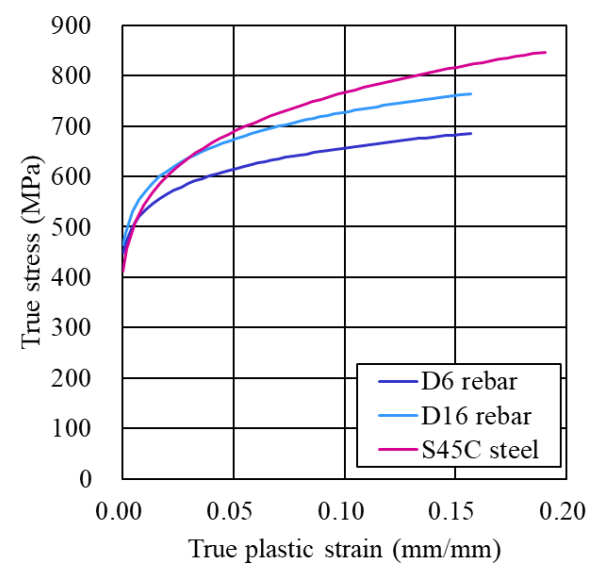

Fig. 8 True stress-true strain relationship.

\subsubsection{Rigid projectiles}

S45C steel (JIS standard) and A5083 (JIS standard) aluminum are utilized to model the material properties for the front and rear components of the rigid projectiles, respectively. The specific parameters describing the material properties are listed in Table 3. Since an identical mass $(3.6 \mathrm{~kg})$ is required to ensure that the projectile's mass does not affect the local damage of the RC panel, the density of each component has been slightly adjusted. 
Table 3 Material properties of projectiles.

\begin{tabular}{|c|c|c|c|}
\hline & Unit & S45C steel & Aluminum \\
\hline Young's modulus & {$[\mathrm{MPa}]$} & 214,000 & 72,000 \\
\hline Yield stress & {$[\mathrm{MPa}]$} & 411.9 & 195 \\
\hline Nominal tensile strength & {$[\mathrm{MPa}]$} & 705.1 & 345 \\
\hline True tensile strength & {$[\mathrm{MPa}]$} & 846.1 & - \\
\hline True fracture strain & {$[\mathrm{mm} / \mathrm{mm}]$} & 0.1906 & - \\
\hline Fracture strain & {$[\mathrm{mm} / \mathrm{mm}]$} & 0.5 & - \\
\hline Poisson's ratio & & 0.3 & 0.33 \\
\hline
\end{tabular}

\subsubsection{Soft projectiles}

S45C steel (JIS standard) is used to study the material properties of soft projectiles. To maintain the same mass $(3.6 \mathrm{~kg})$ for two types of soft projectiles, the configuration of the hemispherical nose part has been slightly adjusted. The true stress-true strain relationship for the S45C material is plotted in Fig. 8.

\section{Definition of the impact conditions}

In the simulation analyses, three types of contact conditions are defined between the rigid projectile and the RC panel. The contact conditions and friction coefficients used in the analyses are summarized in Table 4. To determine the internal energy and resulting local damage of the RC panel, the number of ruptured elements in the RC model should be confirmed. Therefore, an eroding contact condition is set between the projectile and the concrete. The ruptured elements that exceed the failure strain of the material during the impact are removed. All of these conditions are based on contact calculations performed using the penalty method.

Due to the differences in the element properties, the contact between the projectile and the steel rebar is defined as the contact between a solid element and a beam element in the simulation analysis. The node to surface contact condition can adequately represent the projectile-steel rebar contact. A single surface contact is defined for the case in which the deformed projectile (or a fragment of the ruptured projectile) contacts itself. Using these conditions, the contact calculations are implemented using the penalty method. In addition, the friction coefficient for each contact condition is not always known, so we adopted generic values that are widely used in contact calculations (Architecture Handbook, 1977).

Table 4 Definition of the contact conditions.

\begin{tabular}{|c|c|c|}
\hline Object & Contact condition & Friction coefficient \\
\hline Projectile-concrete & Eroding & 0.3 \\
\hline Projectile-rebar & Node to surface & 0.2 \\
\hline Self-contact of projectile & Single surface & 0.2 \\
\hline
\end{tabular}

The boundary conditions of the RC panel are fully fixed by restricting the steel pipe located at the four corners of the RC panel.

In this work, eight cases are investigated to verify the effect of the projectile's nose shape on the local damage of RC panel subjected to normal or oblique impact by rigid or soft projectile, as summarized in Table 5. Graphical representations of the RC panel and the projectile for each case prior to the impact are shown in Fig. 9. 
Table 5 Cases considered in the impact simulation analysis.

\begin{tabular}{|c|c|c|c|c|}
\hline Case & Impact angle & Impact velocity & Projectile type & Projectile nose shape \\
\hline 1 & $0^{\circ}$ & \multirow{8}{*}{$201 \mathrm{~m} / \mathrm{s}$} & \multirow{4}{*}{ Rigid } & Flat \\
\hline 2 & $0^{\circ}$ & & & Hemispherical \\
\hline 3 & $45^{\circ}$ & & & Flat \\
\hline 4 & $45^{\circ}$ & & & Hemispherical \\
\hline 5 & $0^{\circ}$ & & \multirow{4}{*}{ Soft } & Flat \\
\hline 6 & $0^{\circ}$ & & & Hemispherical \\
\hline 7 & $45^{\circ}$ & & & Flat \\
\hline 8 & $45^{\circ}$ & & & Hemispherical \\
\hline
\end{tabular}

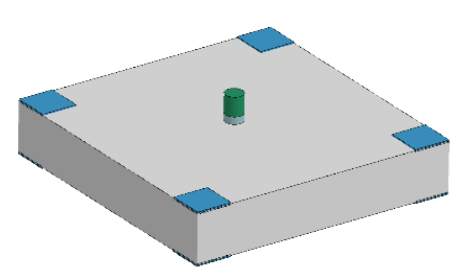

Case 1

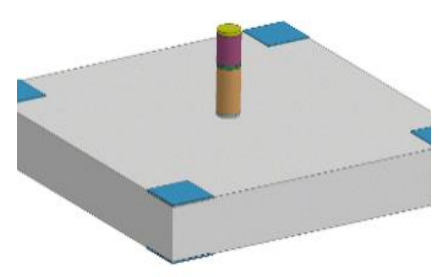

case 5

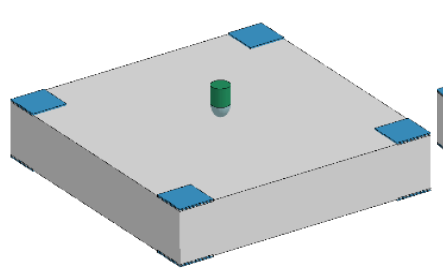

Case 2

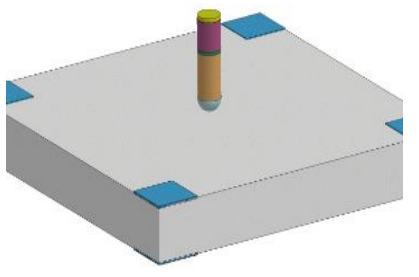

case 6

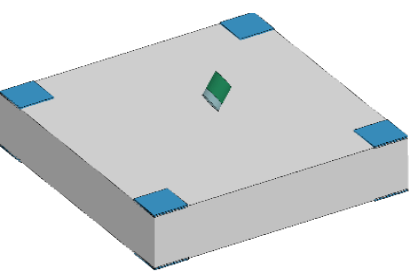

Case 3

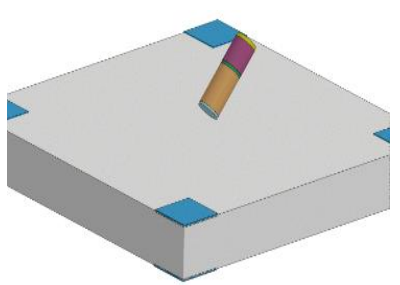

case 7

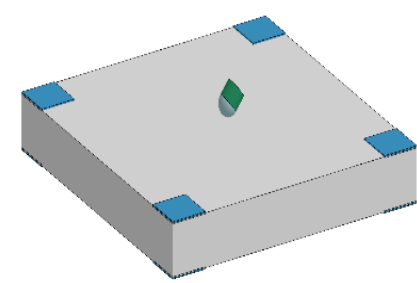

Case 4

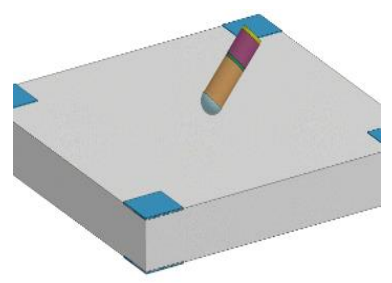

case 8

Fig. 9 Illustration of the projectile and the RC panel for each case.

\section{Analytical results}

\subsection{Impact behavior of the RC panel and the projectiles}

\subsubsection{Rigid projectiles}

In the numerical simulations, the end time of the impact calculations is set to $50 \mathrm{~ms}$ to allow for a thorough study of the projectile trajectory and the damage caused on the RC panel. The damage observed at the final stage of the calculation $(\mathrm{t}=50 \mathrm{~ms})$, following the normal impact of rigid projectile with flat or hemispherical nose shape, is illustrated in Fig. 10.

To distinguish the differences in local damage to the RC panel caused by the flat and hemispherical projectiles, the penetration depth and crater dimensions are summarized in Table 6. Clearly, the crater size in Case 1 (flat nose) is larger than that in Case 2 (hemispherical nose), whereas similar penetration depths are observed in both cases. For the rear surface of the RC panel, the region of crack distribution in Case 1 is broader than that in Case 2. In other words, craters caused by penetration occurred on the surface of the panel, and cracks occurred on both surfaces of the RC panel due to the progression of the shear cone. For normal impact, rigid projectile with flat nose exerted more local damage on the RC panel than rigid projectile with hemispherical nose.

Next, the corresponding simulation results for oblique impact are shown in Fig. 11. The penetration depth and crater dimensions for oblique impact are summarized in Table 6 for Cases 3 and 4. The penetration depth of the hemispherical projectile is greater than that of the flat projectile; however, the crater for the flat projectile is wider than that for the hemispherical projectile, indicating that the volumes of ruptured solid concrete elements are similar in both cases for oblique impact. The simulation results indicate that slight cracks occur on the rear surface of the RC panel in Case 3, whereas an undamaged surface is obtained in Case 4. 


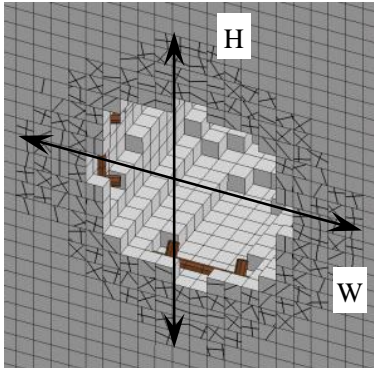

Case 1 (front view)

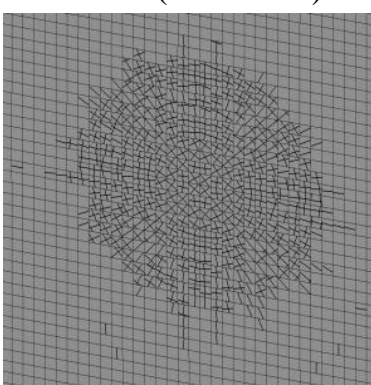

Case 1 (rear view)

Rigid Projectile

(Flat nose)

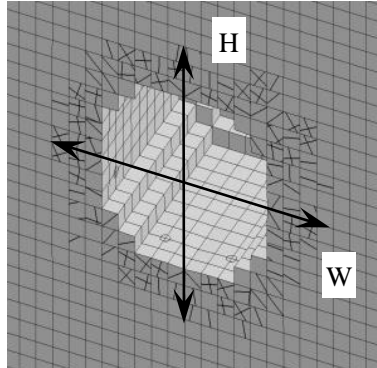

Case 2 (front view)

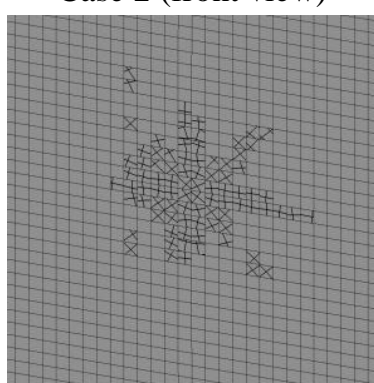

Case 2 (rear view)

Rigid Projectile

(Hemispherical nose)

Fig. 10 Schematic representation of the local damage caused by the impact of rigid projectile (impact angle: $0^{\circ}$ ).

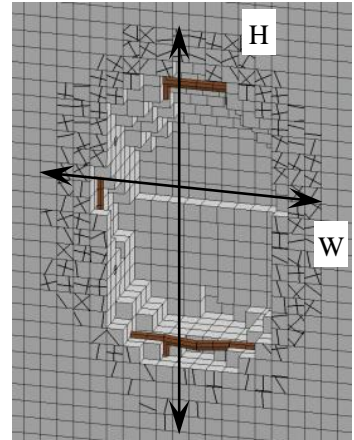

Case 3 (front view)

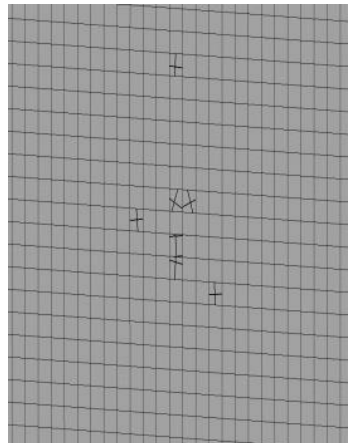

Case 3 (rear view) Rigid Projectile (Flat nose)

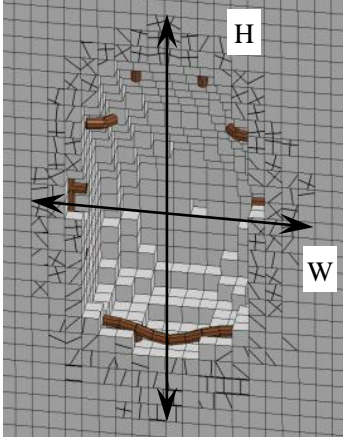

Case 4 (front view)

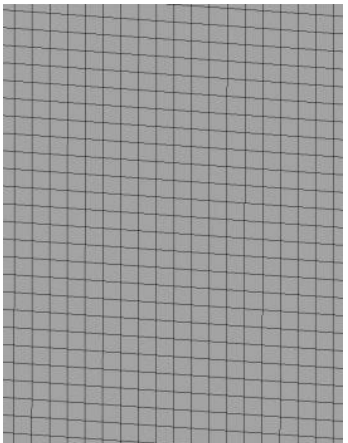

Case 4 (rear view)

Rigid Projectile

(Hemispherical nose)

Fig. 11 Schematic representation of the local damage caused by the impact of rigid projectile (impact angle: $45^{\circ}$ ). 
Kang, Nishida, Okuda, Tsubota and Li, Mechanical Engineering Journal, Vol.7, No.3 (2020)

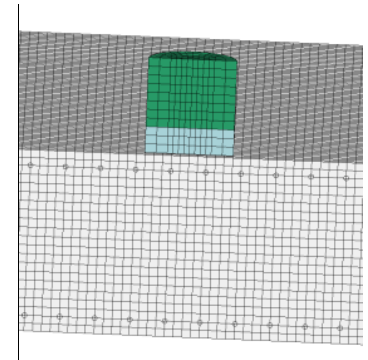

$\mathrm{t}=0 \mathrm{~ms}$

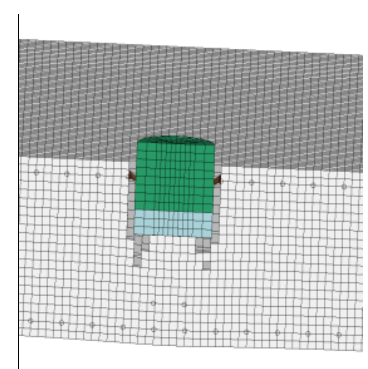

$\mathrm{t}=1 \mathrm{~ms}$

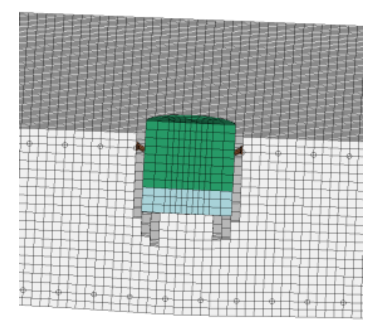

$\mathrm{t}=2 \mathrm{~ms}$

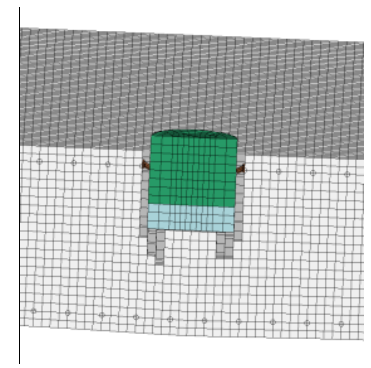

$\mathrm{t}=4 \mathrm{~ms}$

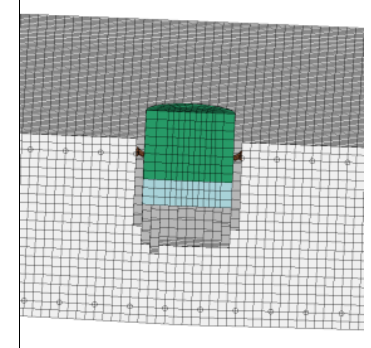

$\mathrm{t}=10 \mathrm{~ms}$

(Case 1)

Flat nose

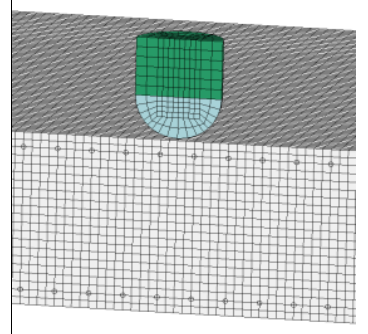

$\mathrm{t}=0 \mathrm{~ms}$

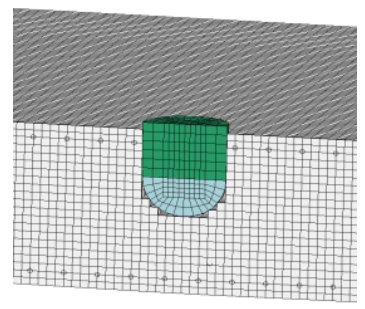

$\mathrm{t}=1 \mathrm{~ms}$

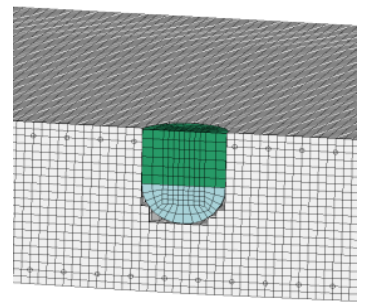

$\mathrm{t}=2 \mathrm{~ms}$

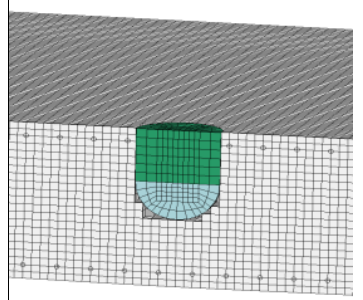

$\mathrm{t}=4 \mathrm{~ms}$

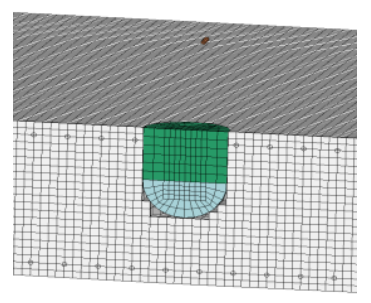

$$
\mathrm{t}=10 \mathrm{~ms}
$$

(Case 2)

Hemispherical nose

Fig. 12 Normal impact of soft projectiles for Cases 1 and 2.
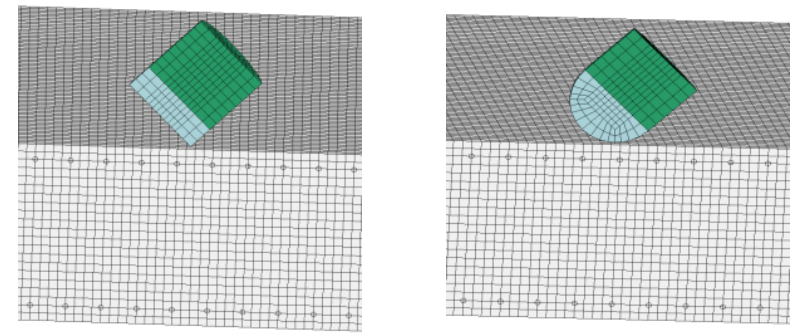

$\mathrm{t}=0 \mathrm{~ms}$

$\mathrm{t}=0 \mathrm{~ms}$

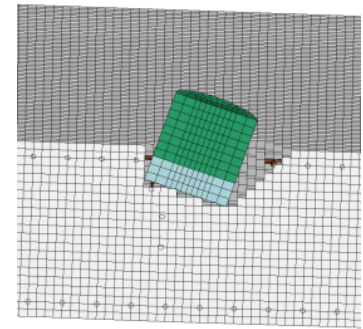

$\mathrm{t}=1 \mathrm{~ms}$

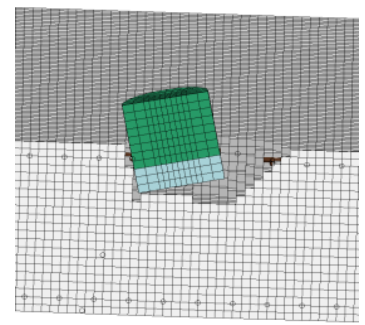

$\mathrm{t}=2 \mathrm{~ms}$

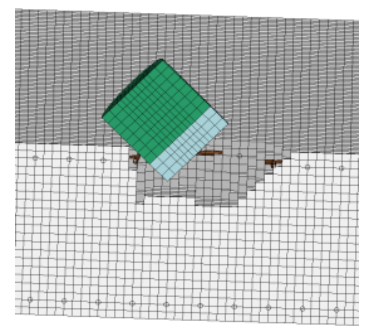

$\mathrm{t}=4 \mathrm{~ms}$

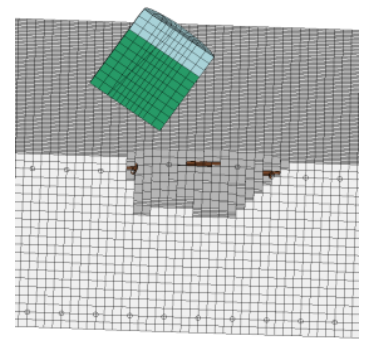

$\mathrm{t}=10 \mathrm{~ms}$

(Case 3)

Flat nose

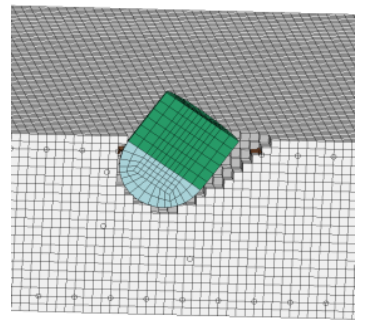

$\mathrm{t}=1 \mathrm{~ms}$

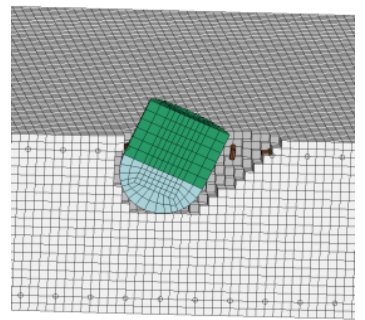

$\mathrm{t}=2 \mathrm{~ms}$

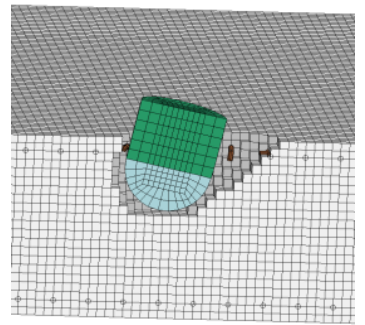

$\mathrm{t}=4 \mathrm{~ms}$

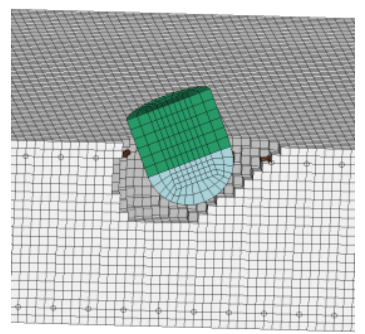

$$
\mathrm{t}=10 \mathrm{~ms}
$$$$
\text { (Case 4) }
$$

Hemispherical nose

Fig. 13 Oblique impact of soft projecitles for Cases 3 and 4. 
Table 6 Simulation results of the RC panel.

\begin{tabular}{|c|c|c|c|c|c|}
\hline \multirow{2}{*}{ Case } & \multirow{2}{*}{ Penetration depth } & $\begin{array}{c}\text { Crater dimension } \\
(\mathrm{W} \times \mathrm{H})\end{array}$ & Projectile & Nose shape & Impact angle \\
\cline { 4 - 6 } & & $120 \mathrm{~mm} \times 120 \mathrm{~mm}$ & Rigid & Flat & $0^{\circ}$ \\
\hline 1 & $120 \mathrm{~mm}$ & $1201 \mathrm{~mm} \times 101 \mathrm{~mm}$ & Rigid & Hemispherical & $0^{\circ}$ \\
\hline 2 & $120 \mathrm{~mm}$ & $101 \mathrm{~mm}$ & Rigid & Flat & $45^{\circ}$ \\
\hline 3 & $70 \mathrm{~mm}$ & $120 \mathrm{~mm} \times 190 \mathrm{~mm}$ & Rigid & Hemispherical & $45^{\circ}$ \\
\hline 4 & $100 \mathrm{~mm}$ & $120 \mathrm{~mm} \times 180 \mathrm{~mm}$ & \multicolumn{3}{|c|}{} \\
\hline
\end{tabular}

Comparisons of the detailed penetration behaviors for rigid projectiles with flat or hemispherical noses are presented in Fig. 12 for normal impact and Fig. 13 for oblique impact.

In the case of normal impact, both types of projectiles penetrated the RC panel, forming a cylindrical hole in it. The initial penetration depth for Case 1 with flat projectile was below that for hemispherical projectile prior to 4 ms. A ring-shaped damage zone occurred on the RC panel around the nose part of the flat rigid projectile, which can be attributed to the stress concentration around the nose of the projectile. Subsequently, at $\mathrm{t}=10 \mathrm{~ms}$, a few solid elements below the front surface of the flat projectile split from the RC panel, resulting in the same penetration depth obtained with the hemispherical projectile. Therefore, secondary damages of the RC panel were observed in the case of flat projectile, which rebounded slightly within the specimen. In the case of hemispherical projectile, all the kinematic energy from the projectile was absorbed by the RC panel, and no spalling of the concrete solid elements occurred.

In contrast, for the oblique impact, the results obtained for both Cases 3 (with flat nose projectile) and 4 (with hemispherical nose projectile) indicate that the rigid projectiles colliding with the RC specimen slightly rebounded, exhibiting a rotational motion, and a conical damage zone was formed as a result of the incident angle. Moreover, the penetration depth decreased compared with the normal impact case, and there was no secondary destruction of the RC panel at $0-10 \mathrm{~ms}$. Furthermore, the surface-damage depth caused by the hemispherical projectile, regarded as the maximum depth of the crater measured along the direction normal to the target surface, was greater than that for the flat projectile.

\subsubsection{Empirical formula}

The NDRC formula (NDRC, 1946) was originally introduced to consider the nose shape factor and ensure robustness in evaluating the penetration depths of rigid projectiles normally penetrating a massive concrete target. Later, Kennedy $(1966,1976)$ defined the concrete penetrability in terms of $f_{c}$ by fitting to experimental data to modify the NDRC formula for larger projectile diameters. First, the present modified NDRC penetration formula, defined by a $\mathrm{G}$ function, is given as:

$$
\begin{aligned}
& \frac{x}{d}= \begin{cases}2 G^{0.5} & \frac{x}{d} \leq 2 \\
G+1 & \frac{x}{d} \geq 2\end{cases} \\
& \mathrm{G}=3.8 \times 10^{-5} \frac{N^{*} M}{d \sqrt{f_{c}}}\left(\frac{V_{0}}{d}\right)^{1.8}
\end{aligned}
$$

where:

$x$ : surface-damage depth $(\mathrm{m})$;

$d$ : diameter of the projectile $(\mathrm{m})$;

$N^{*}$ : nose shape factor $(0.72$ for a flat nose; 0.84 for a blunt nose; 1.0 for a spherical end nose; 1.14 for a very sharp nose);

$M$ : mass of the projectile $(\mathrm{kg})$;

$V_{0}$ : projectile impact velocity $(\mathrm{m} / \mathrm{s})$;

$f_{c}$ : unconfined concrete compressive strength $\left(\mathrm{N} / \mathrm{m}^{2}\right)$.

In addition, the formula to evaluate the surface-damage depth for oblique impact can be defined as (Ohta et al., 2017): 


$$
\begin{aligned}
x_{\theta} & =\left\{\begin{array}{cc}
2 G_{\theta}^{0.5} \frac{d}{\cos \theta} & x \leq 2 d \\
\left(G_{\theta}+1\right) \frac{d}{\cos \theta} \quad x \geq 2 d
\end{array}\right. \\
G_{\theta} & =3.8 \times 10^{-5} \frac{N^{*} M \cos \theta}{d \sqrt{f_{c}}}\left(\frac{V_{0} \cos \theta^{2}}{d}\right)^{1.8}
\end{aligned}
$$

The correction definition related to the effect of slip and rebound is:

$$
b_{\theta}=e^{\left(\mu_{k}-\frac{f_{c}}{F_{s}}\right)}
$$

Finally, the surface-damage depth is obtained by multiplying the correction parameter:

where:

$$
x_{\theta}^{\prime}=b_{\theta} \times x_{\theta}
$$

$\theta$ : impact angle;

$F_{S}:$ impact stress;

$\mu_{k}$ : coefficient of dynamic friction

The precision of the calculated penetration depth was validated by comparison with the analytical results obtained by the modified NDRC formula for normal impact, as shown in Table 7. At a speed of $201 \mathrm{~m} / \mathrm{s}$, the influences of the nose shapes of the projectiles on the surface penetration depth of the RC panel were similar and the simulation results of this work agreed well with the reference solutions.

Moreover, the simulation results related to the penetration depth for oblique impact by two kinds of projectiles were verified using a reference solution derived from the Ohta formula, which was developed by considering the effects of the impact angle on the velocity, diameter, and slip/rebound. A validation of the Ohta formula was implemented based on the experimental results (Beth, 1943). The results of the comparisons are summarized in Table 8 , and based on the data shown in Tables 7 and 8, it can be observed that the penetration depths obtained in this study agreed well with the analytical solutions. The validated results show that the rigid projectile with hemispherical nose penetrated almost 1.4 times deeper into the target than the rigid projectile with flat nose.

Table 7 Comparison of penetration depths (normal impact).

\begin{tabular}{|c|c|c|c|}
\hline \multicolumn{2}{|c|}{ Flat Nose } & \multicolumn{2}{c|}{ Hemispherical Nose } \\
\hline 3D FEM & Modified & 3D FEM & Modified \\
Analysis & NDRC & Analysis & NDRC \\
\hline $120.0 \mathrm{~mm}$ & $118.2 \mathrm{~mm}$ & $120.0 \mathrm{~mm}$ & $125.0 \mathrm{~mm}$ \\
\hline
\end{tabular}

Table 8 Comparison of penetration depths (oblique impact).

\begin{tabular}{|c|c|c|c|}
\hline \multicolumn{2}{|c|}{ Flat Nose } & Hemispherical Nose \\
\hline $\begin{array}{c}\text { 3D FEM } \\
\text { Analysis }\end{array}$ & $\begin{array}{c}\text { Ohta } \\
\text { Method }\end{array}$ & $\begin{array}{c}\text { 3D FEM } \\
\text { Analysis }\end{array}$ & $\begin{array}{c}\text { Ohta } \\
\text { Method }\end{array}$ \\
\hline $70.0 \mathrm{~mm}$ & $70.4 \mathrm{~mm}$ & $100.0 \mathrm{~mm}$ & $95.2 \mathrm{~mm}$ \\
\hline
\end{tabular}

\subsubsection{Soft projectiles}

In the numerical simulations, the end time of the impact calculations are set to be $50 \mathrm{~ms}$ to fully capture the trajectory of the projectiles and the damage situation of the RC panel. Firstly, the damage modes of the RC panels subjected to normal and oblique impacts of soft projectiles with flat and hemispherical nose shapes at the final stages of the calculation $(\mathrm{t}=50 \mathrm{~ms})$ are illustrated in Figs. 14 and 15.

To differentiate the local damages of the RC panels between flat and hemispherical projectiles, the penetration depths and crater dimensions are summarized in Table 9. For the normal impact, it is found that the crater size of the flat case (Case 5) is slightly larger than that of the hemispherical case (Case 6), and the penetration depths for Cases 5 and 6 are almost the same. For the rear surface of the RC panel, the region of crack distribution for Case 5 is broader than that for Case 6.

For the oblique impact, the crater size of the flat nose shape case (Case 7) is slightly larger than that of the hemispherical nose shape case (Case 8), and the results for the oblique impact case are larger than those for the normal impact case, especially in the vertical direction. The penetration depth in the hemispherical case is slightly greater than 
that in the flat case.

It is found that the soft projectile with the hemispherical nose shape influenced the local damage of the RC panel more than the soft projectile with the flat nose shape in terms of penetration depth.

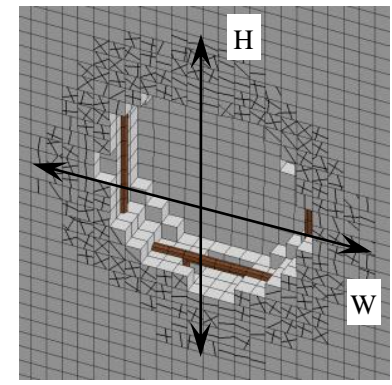

case 5 (front view)

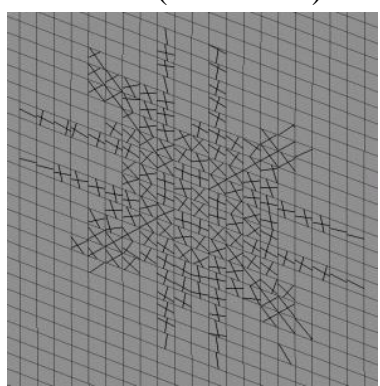

case 5 (rear view)

Soft Projectile

(Flat nose)

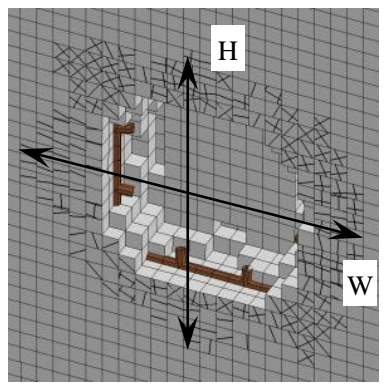

case 6 (front view)

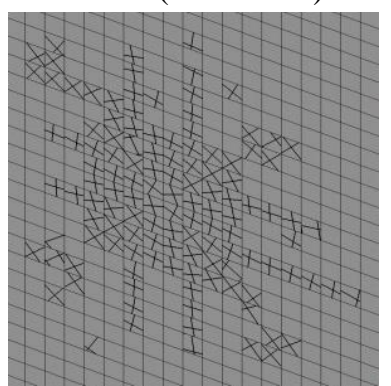

case 6 (rear view)

Soft Projectile

(Hemispherical nose)

Fig. 14 Schematic representation of the local damage of RC panel after the impact of soft projectile (impact angle: $0^{\circ}$ ).

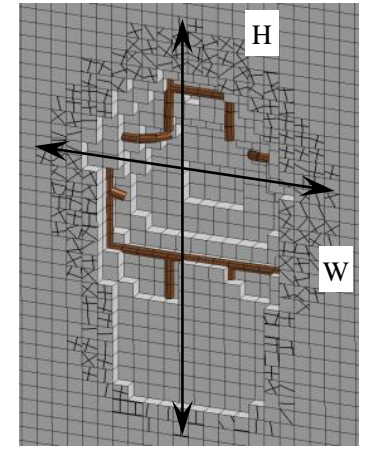

case 7 (front view)

Soft Projectile

(Flat nose)

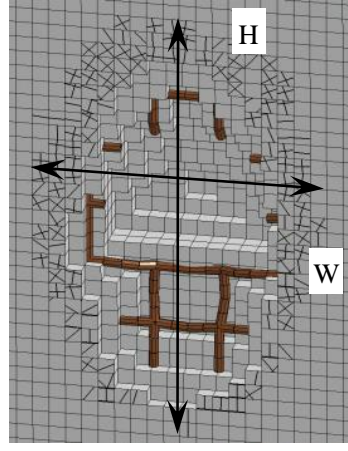

case 8 (front view)

Soft Projectile

(Hemispherical nose)

Fig. 15 Schematic representation of the local damage of RC panel after the impact of soft projectile (impact angle: $45^{\circ}$ ).

Table 9 Simulation results of the RC panel.

\begin{tabular}{|c|c|c|c|c|c|}
\hline \multirow{2}{*}{ Case } & \multirow{2}{*}{ Penetration depth } & $\begin{array}{c}\text { Crater dimension } \\
(\mathrm{W} \times \mathrm{H})\end{array}$ & Projectile & Nose shape & Impact angle \\
\cline { 4 - 6 } & & $129 \mathrm{~mm} \times 140 \mathrm{~mm}$ & Soft & Flat & $0^{\circ}$ \\
\hline 5 & $50 \mathrm{~mm}$ & $120 \mathrm{~mm} \times 130 \mathrm{~mm}$ & Soft & Hemispherical & $0^{\circ}$ \\
\hline 6 & $50 \mathrm{~mm}$ & $120 \mathrm{~mm} \times 240 \mathrm{~mm}$ & Soft & Flat & $45^{\circ}$ \\
\hline 7 & $50 \mathrm{~mm}$ & $140 \mathrm{~mm}$ & Soft & Hemispherical & $45^{\circ}$ \\
\hline 8 & $70 \mathrm{~mm}$ & $130 \mathrm{~mm} \times 240 \mathrm{~mm}$ & \multicolumn{3}{|c|}{} \\
\hline
\end{tabular}


Kang, Nishida, Okuda, Tsubota and Li, Mechanical Engineering Journal, Vol.7, No.3 (2020)

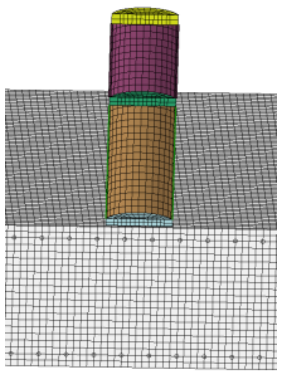

$\mathrm{t}=0 \mathrm{~ms}$

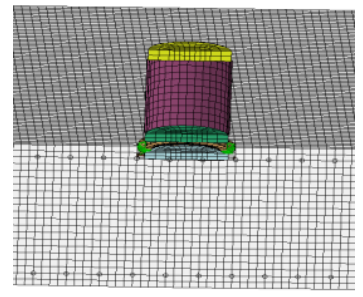

$\mathrm{t}=1 \mathrm{~ms}$

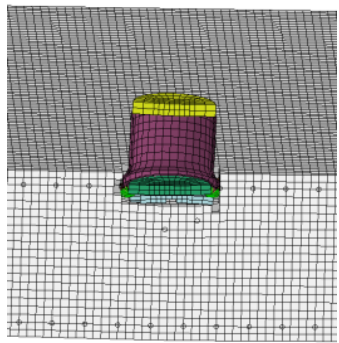

$\mathrm{t}=2 \mathrm{~ms}$

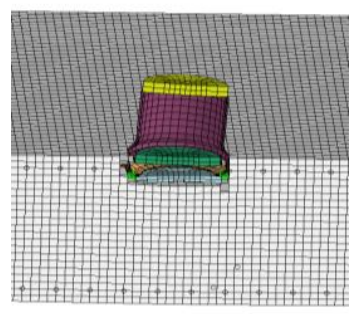

$\mathrm{t}=4 \mathrm{~ms}$

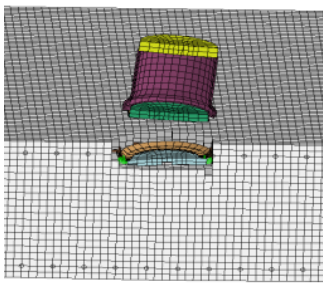

$\mathrm{t}=10 \mathrm{~ms}$

(case5)

Flat nose

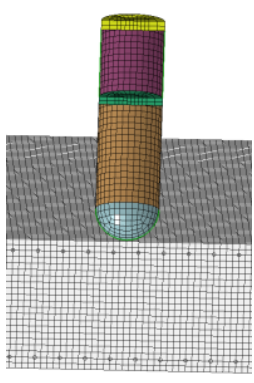

$\mathrm{t}=0 \mathrm{~ms}$

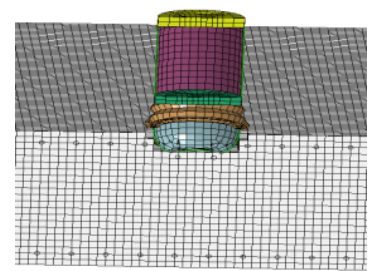

$\mathrm{t}=1 \mathrm{~ms}$

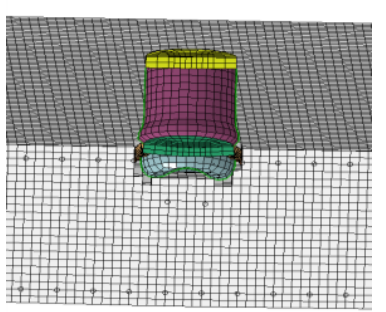

$\mathrm{t}=2 \mathrm{~ms}$

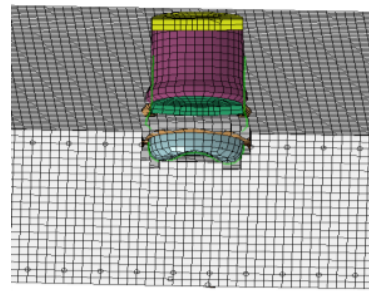

$\mathrm{t}=4 \mathrm{~ms}$

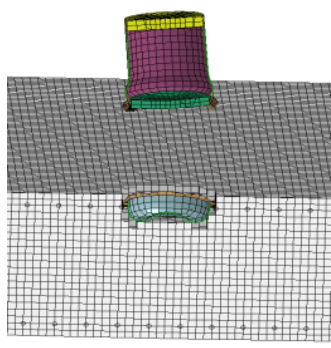

$\mathrm{t}=10 \mathrm{~ms}$

(case6)

Hemispherical nose

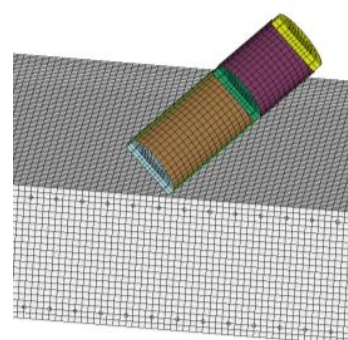

$\mathrm{t}=0 \mathrm{~ms}$

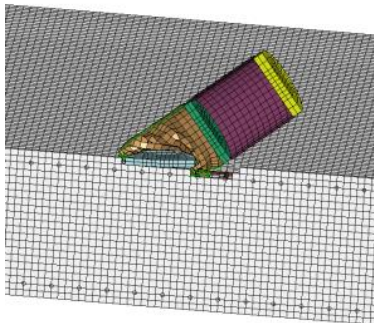

$\mathrm{t}=1 \mathrm{~ms}$

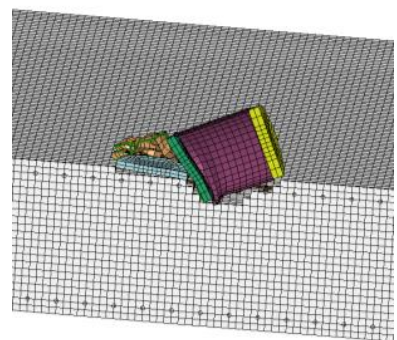

$\mathrm{t}=2 \mathrm{~ms}$

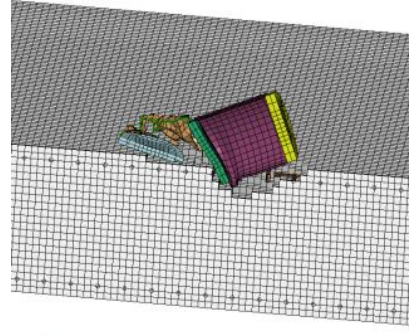

$\mathrm{t}=4 \mathrm{~ms}$

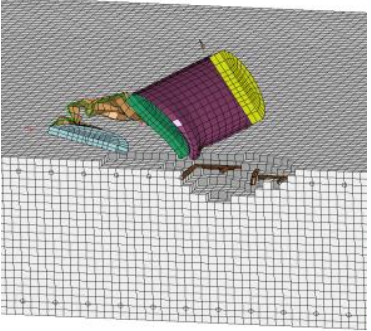

$\mathrm{t}=10 \mathrm{~ms}$

(case7)

Flat nose

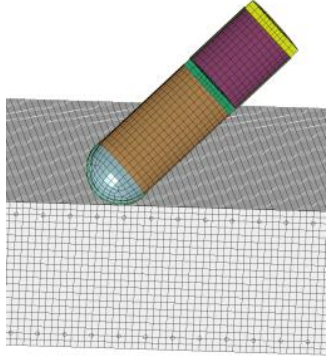

$\mathrm{t}=0 \mathrm{~ms}$

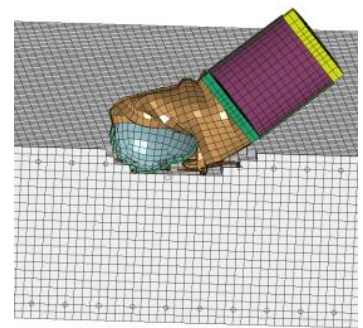

$\mathrm{t}=1 \mathrm{~ms}$

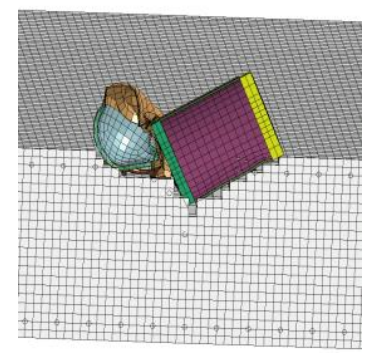

$\mathrm{t}=2 \mathrm{~ms}$

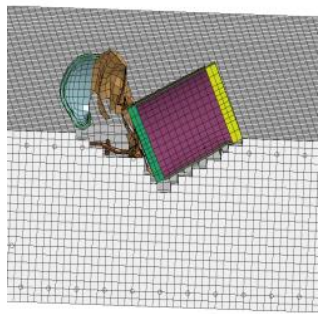

$\mathrm{t}=4 \mathrm{~ms}$

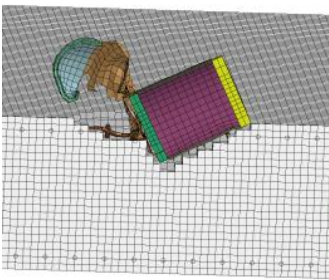

$\mathrm{t}=10 \mathrm{~ms}$

(case8)

Hemispherical nose

Fig. 17 Oblique impact of soft projecitles for Cases 7 and 8 .

Fig. 16 Normal impact of soft projectiles for Cases 5 and 6. 
Images from the simulation analyses are displayed in Figs. 16 and 17 to illustrate the time progression of the impact behavior derived from normal and oblique impacts by soft projectiles with flat and hemispherical nose shapes.

For the case of the normal impact (Fig. 16), shallower surface penetration depths are observed on the RC panel for the two types of projectiles, compared with the results obtained by rigid projectile (as described in section 5.1.1). Based on the buckling situation of the projectiles for Case 5 with flat nose and Case 6 with hemispherical nose, it is observed that the front thin-cylindrical-shell part completely buckled, and almost no buckling can be identified for the flat nose part of the flat projectile, whereas severe buckling occurred for both the thin-cylindrical-shell part and the hemispherical nose part of the hemispherical projectile.

According to the impact behavior for the oblique impact case (Fig. 17), the flat projectile impacted the RC panel and rebounded from the surface with a mild rotational motion. In contrast, the hemispherical projectile embeds into the RC panel without separation until the end of the impact ( $\mathrm{t}=50 \mathrm{~ms})$. It is assumed that the main type of energy consumed for the oblique impact is sliding energy, which resulted in the embedding behavior of the hemispherical projectile in the case of oblique impact. Compared to the situation of the normal impact, the buckling of the hemispherical part of the projectile is slighter, which accounts for the lower internal energy consumed in the case of oblique impact by hemispherical projectile.

\subsection{Time history of energy transmission \\ 5.2.1 Rigid projectiles}

In this section, the time history of energy transmission for the RC panel and the projectile is presented to evaluate the influence of the projectile's nose shape on the impact process. Since the energy transmission becomes approximately stable after $\mathrm{t}=3 \mathrm{~ms}$, a partial time history is shown in the following figures.

Figure 18 presents the time history of the internal energy of the RC panel for normal impact. As shown in this figure, the final internal energy of the RC panel for the flat projectile is larger than that for the hemispheric projectile, including an initially ruptured portion and the secondary damage in the target RC panel caused by the impact of the flat rigid projectile. An oscillation of the energy transmission is observed in the time history for the flat projectile, whereas the results for the hemispherical projectile present a smooth internal energy transmission for the RC panel. This result is consistent with the analysis of the destruction process after impact for the two types of rigid projectiles, as described in the previous section.

Figure 19 presents the time history of the kinematic energy of the RC panel. Similar behaviors are observed for the impacts caused by the flat and hemispherical projectiles. These results indicate that the kinematic energy of the RC panel becomes stable at approximately $0.8 \mathrm{~ms}$, with no further increases.

Similarly, the impact of the flat projectile caused energy oscillations during the impact process. Thus, the projectile's nose shape does not strongly influence the kinematic energy of the RC panel in the case of normal impact.

Figure 20 shows the time history of the kinematic energy of the projectiles for normal impact. For both the flat and hemispherical projectiles, nearly all the kinematic energy was consumed by 1.1-1.4 ms. The results demonstrate that the kinematic energy of the flat projectile decreased more rapidly than that of the hemispherical projectile.

For the oblique impact by rigid projectile, the time history of the energy transmission process is presented in Figs. 21-23, following the pattern presented for the energy analysis for the normal impact. With respect to the time history of the internal energy of the RC panel and the projectile kinematic energy, no apparent differences are observed between the two projectile nose shapes, indicating that the influence of the nose shape of rigid projectile is negligible, as shown in Figs. 21 and 23. Fig. 22 indicates that the flat projectile transferred more kinematic energy to the RC panel than the hemispherical projectile at $\mathrm{t}=0.8 \mathrm{~ms}$. However, the difference is slight.

Since both types of rigid projectiles are non-deformable, the internal energy of the projectile due to the impact is very small; thus, the evaluation of the time history of the internal energy for rigid projectiles is not presented here. 


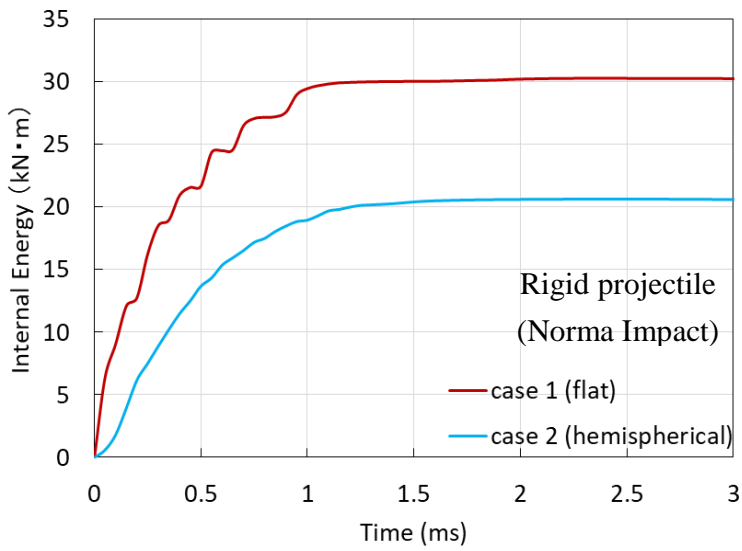

Fig. 18 Time histories of the internal energy for the RC panel in Cases 1 and 2.

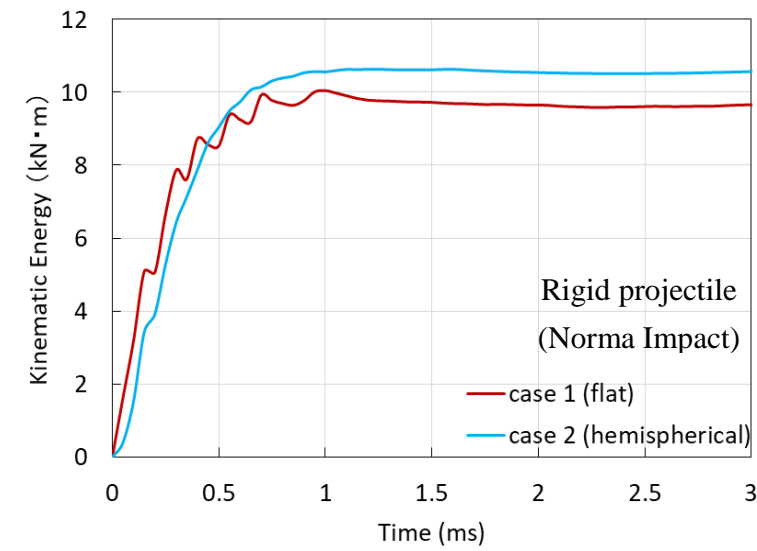

Fig. 19 Time histories of the kinematic energy for the RC panel in Cases 1 and 2.

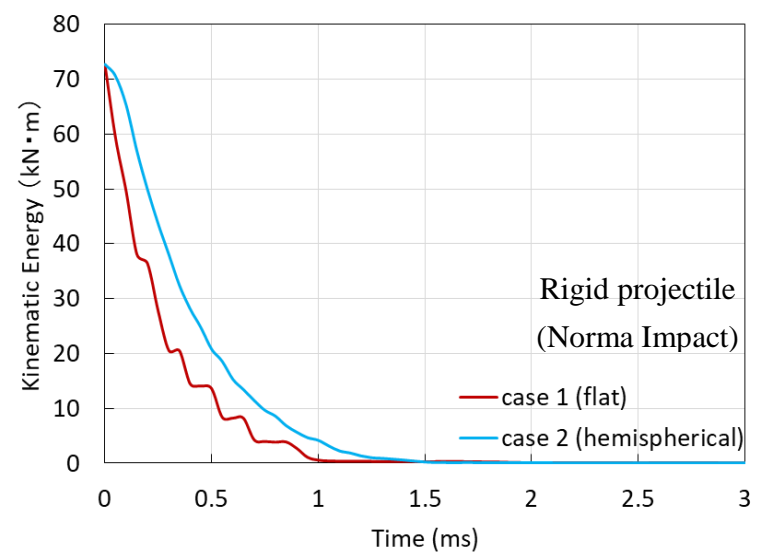

Fig. 20 Time histories of the kinematic energy of the projectile in Cases 1 and 2.

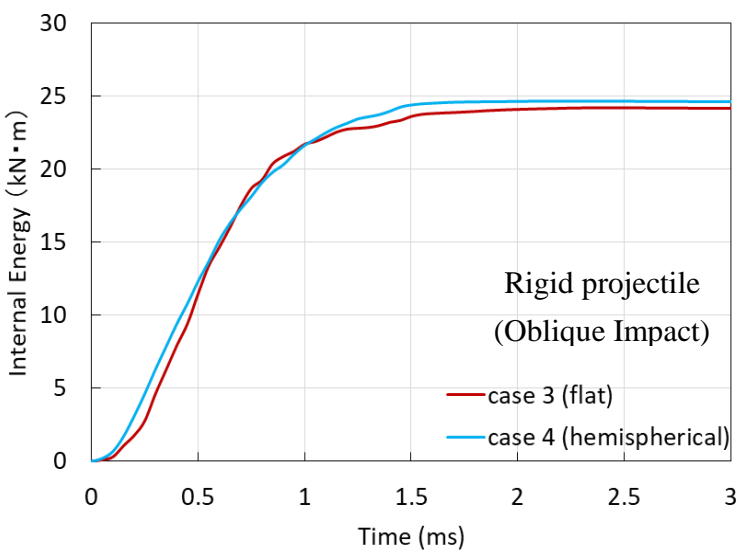

Fig. 21 Time histories of the internal energy of the RC panel for Cases 3 and 4.

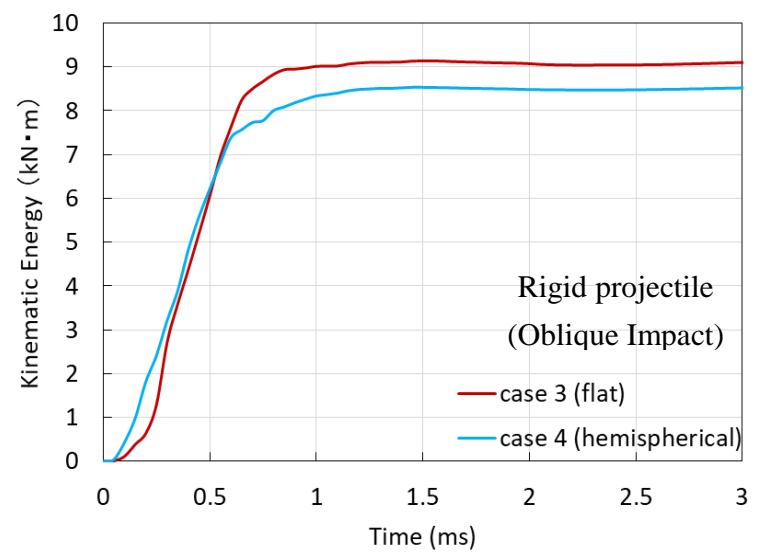

Fig. 22 Time histories of the kinematic energy of the RC panel for Cases 3 and 4. 


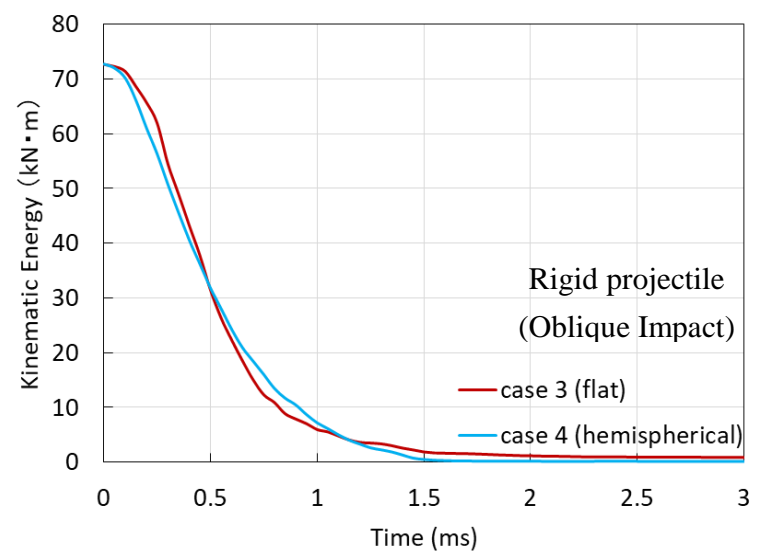

Fig. 23 Time histories of the kinematic energy of the projectile for Cases 3 and 4 .

\subsubsection{Soft projectiles}

With the aim of understanding the impact behavior of RC panel with different projectiles, the time history of the energy transmission has been illustrated for each RC panel and projectile.

Figure 24 shows a comparison of the time history of the internal energy of the RC panel for normal impacts with flat and hemispherical types of soft projectiles. The internal energy of the RC panel for the flat projectile is over $50 \%$ higher than that for the hemispherical projectile throughout the simulation. The rapid rising of the RC panel's internal energy is caused by the flat projectile at the beginning of the impact, and the internal energy of the flat type is almost five times larger than that of the hemispherical type when $t=0.1 \mathrm{~ms}$. This phenomenon is supposed to be the influence of the nose with large impact area of flat projectile. Directly after the impact of the flat soft projectile, a disk-shaped damage zone was generated on the central front surface of the RC panel, whereas a relatively smaller damage zone was created by the hemispherical soft projectile.

Figure 25 shows a comparison of the time history of the kinetic energy of the RC panel. Similar tendencies are observed for the normal impacts by flat and hemispherical projectiles.

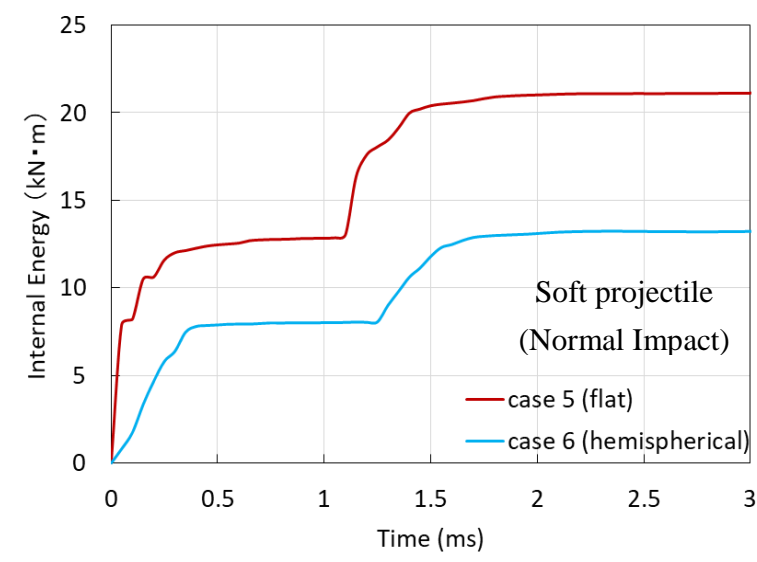

Fig. 24 Comparison of the time histories of the internal energy of the RC panel for Cases 5 and 6.

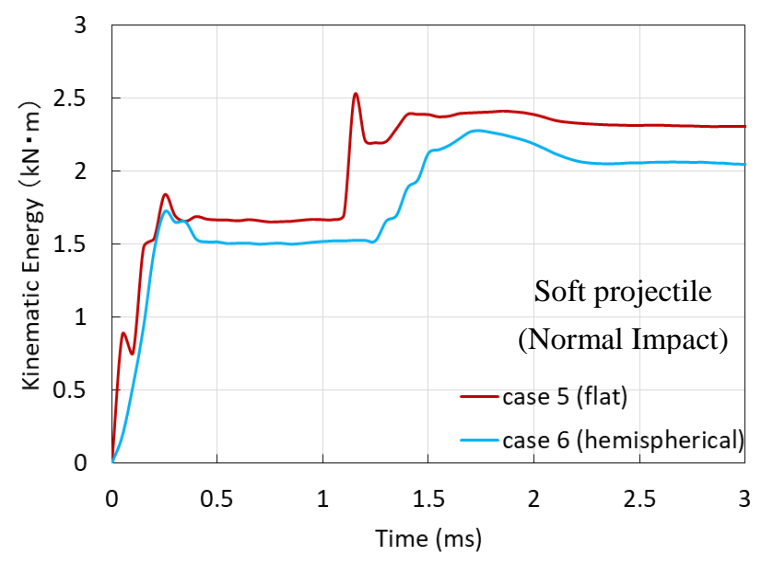

Fig. 25 Comparison of the time histories of the kinematic energy of the RC panel for Cases 5 and 6.

Figures 26 and 27 show the time histories of the internal and kinetic energies of the projectiles for normal impact, and a slight influence of the nose shape can be observed.

Figure 26 shows that the final internal energy of the hemispherical projectile is higher than that of the flat projectile. A possible reason for this is that the hemispherical nose part in Case 6 is damaged by buckling phenomena, whereas almost no damage occurs for the flat nose part in Case 5, as can be seen in Fig. 16. 
By comparing the changes in the internal and kinetic energies for flat and hemispherical projectiles (Figs. 26 and 27 ), it is found that the rate of energy transmission varies at around 1-1.5 ms. The same tendency is observed for the RC panels in Figs. 24 and 25. A possible reason for this is that the distances from the nose top to the middle frame are different in these two projectile models, being slightly longer in the case of hemispherical projectile than in that of the flat projectile, and that may cause a $0.1-0.2 \mathrm{~ms}$ time lag.

Figure 28 shows a comparison of the time histories of the internal energies of the RC panel for oblique impact with flat and hemispherical types of soft projectiles. The internal energy of the RC panel for the hemispherical projectile is higher than that for the flat projectile throughout the simulation, contrary to the case of the normal impact. The corresponding time history of the kinetic energy transmission process for the RC panel is presented in Fig. 29. The differences in nose shape for the soft projectiles hardly affect the internal and kinetic energies of the RC panel. Thus, the results of the oblique impact are different from those of the normal impact.

Figures 30 and 31 show the time histories of the internal and kinetic energies of the projectiles for oblique impact. A higher internal energy of the flat projectile is obtained in this case compared to the hemispherical projectile, as shown in Fig. 30. It is thought that the partial buckling mode of the latter shell part may augment the amount of internal energy of the flat soft projectile, whereas no apparent buckling behavior can be found for the second shell part of the hemispherical soft projectile. Moreover, the nose part of the hemispherical soft projectile exhibits a mild buckling for the duration of the impact. Also, the energy change is more gradual compared to that of the normal impact, and the final differences caused by the nose shape are opposite. Fig. 31 shows that the characteristics of the time history of the projectile's kinetic energy for the oblique impact are similar to those for the normal impact.

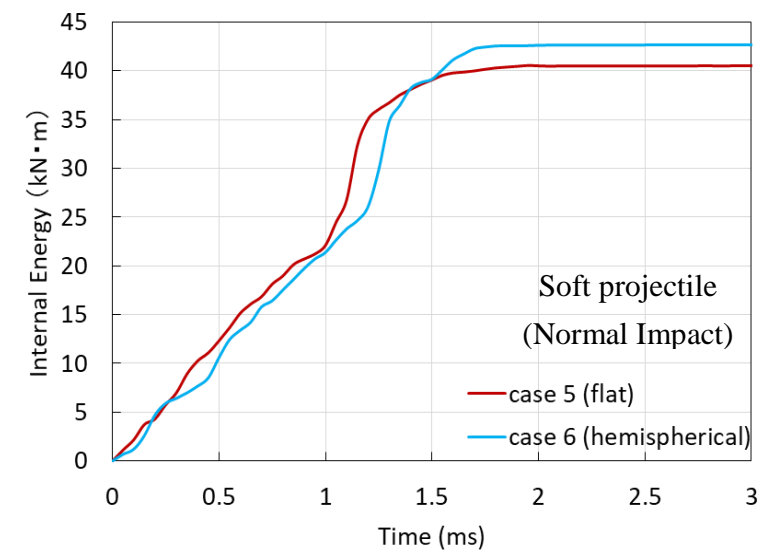

Fig. 26 Comparison of the time histories of the internal energy of the projectile for Cases 5 and 6.

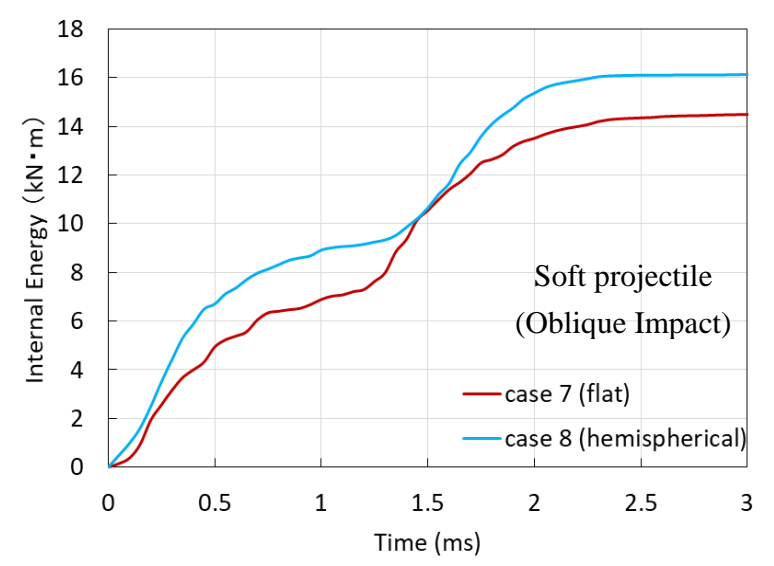

Fig. 28 Comparison of the time histories of the internal energy of the RC panel for Cases 7 and 8.

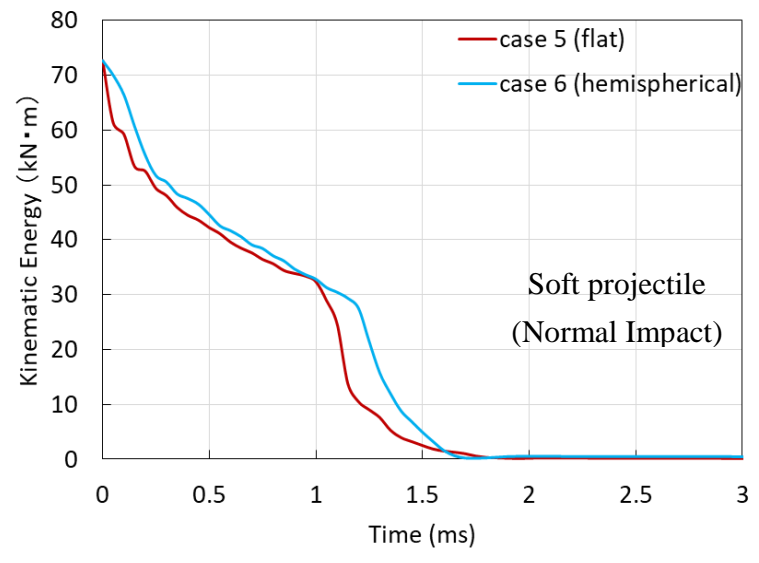

Fig. 27 Comparison of the time histories of the kinematic energy of the projectile for Cases 5 and 6.

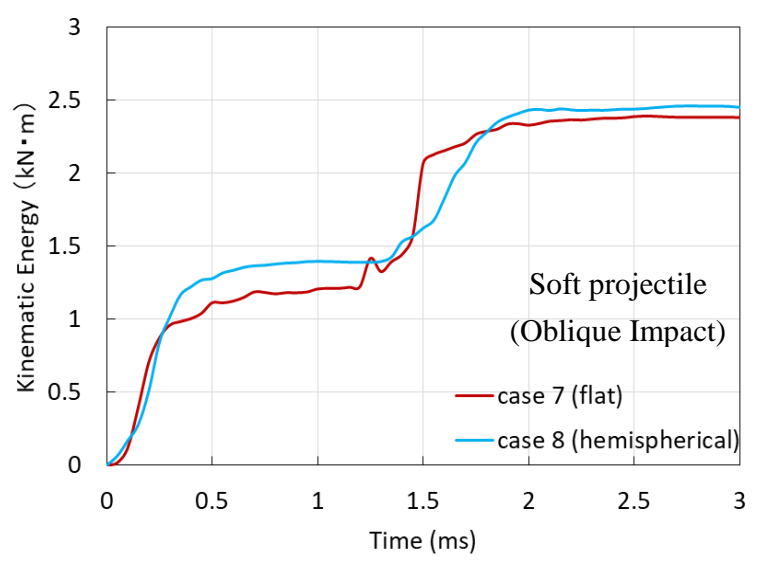

Fig. 29 Comparison of time histories of the kinematic energy of the RC panel for Cases 7 and 8 . 


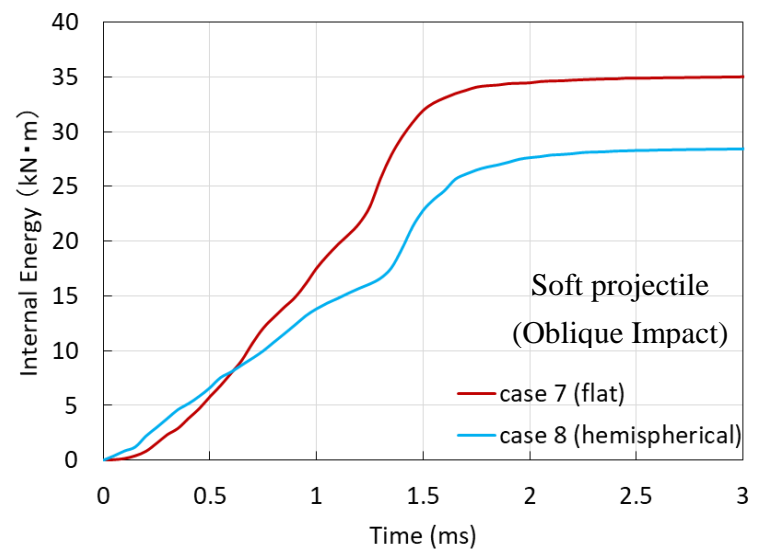

Fig. 30 Comparison of the time histories of the internal energy of the projectile for Cases 7 and 8.

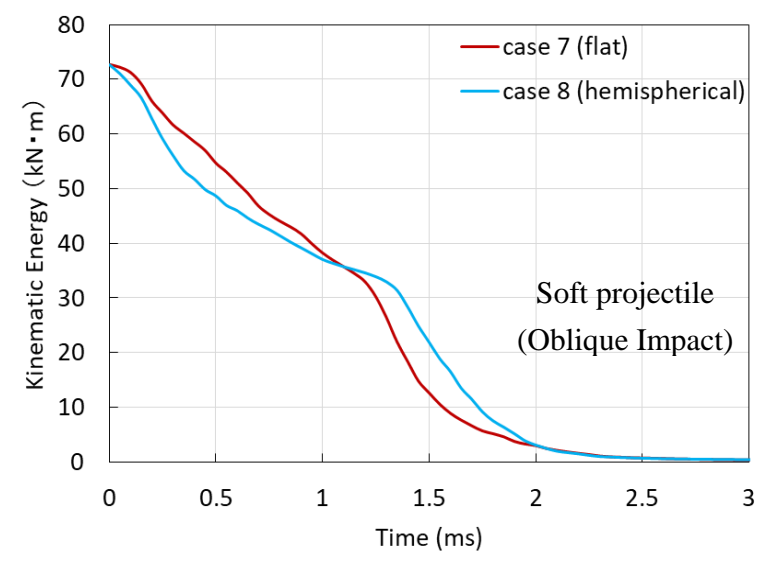

Fig. 31 Comparison of the time histories of the kinematic energy of the projectile for Cases 7 and 8 .

\subsection{Energy-contribution ratio}

\subsubsection{Rigid projectiles}

First, the definitions of the following parameters are presented:

KE: Kinematic energy

IE: Internal energy

Sliding energy: Energy consumed due to friction

The energy-contribution ratios for each impact case involving rigid projectiles at $\mathrm{t}=3 \mathrm{~ms}$ are displayed in Fig. 32 for normal impact and Fig. 33 for oblique impact. The results show that the sliding and internal energies of the RC panel are dominant compared with the other forms of energy in the impact of rigid projectile. Since the contact area between the flat projectile and the RC panel is larger than that between the hemispherical projectile and the panel, the ruptured concrete volume of the RC panel induced by the flat projectile is larger, which explains why the RC internal energy for the flat projectile case is larger than that for the hemispherical projectile case. Although the deformation of the projectile is very small, we find that the internal energy of the flat projectile is higher than that of the hemispherical projectile.

\section{Rigid Projectile}

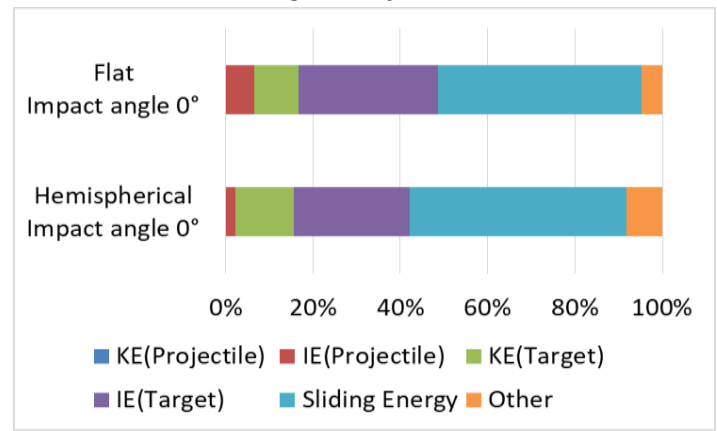

Fig. 32 Energy-contribution ratios for normal impact.
Rigid Projectile

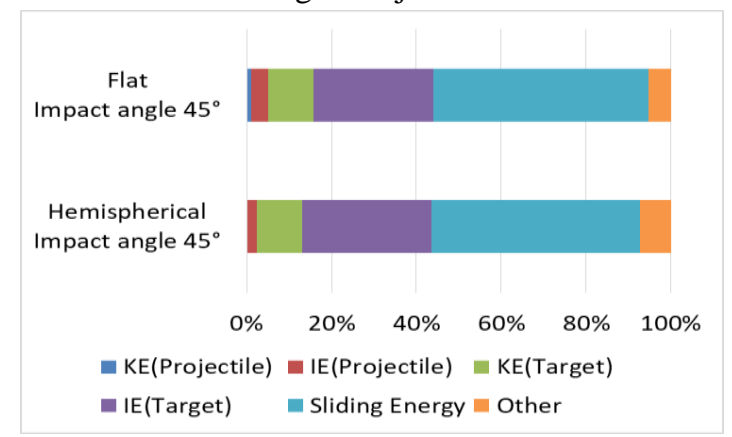

Fig. 33 Energy-contribution ratios for oblique impact.

\subsubsection{Soft projectiles}

Based on the comparison results obtained in each case, it can be found that the internal energies of the projectile and the RC panel for normal impact, and the sliding and internal energies of the projectile for oblique impact, are the dominant kinds of energy involved compared to other kinds of energy for the impact with soft projectiles.

For the normal impact, the hemispherical projectile consumes more internal energy than the flat projectile, as shown in Fig. 34. From the internal energy results of the projectile, it is clear that a complete buckling of the hemispherical nose shape causes more consumption of internal energy for the projectile in the case of normal impact. According to these results, the internal energy of the RC panel for the hemispherical projectile decreases. However, the 
opposite situation is observed for the oblique impact in Fig. 35. The internal energy of the hemispherical projectile is lower than that of the flat projectile. The internal energy of the RC panel for the hemispherical projectile case is slightly higher than that for the flat projectile case. The physical meaning of this phenomenon can be explained by the slip of the hemispherical nose, which induces a slight buckling of the hemispherical projectile. Therefore, the sliding energy for the oblique impact is higher than that for the normal impact due to the influence of the slip from the nose part. Also, for the two cases of oblique impact, the hemispherical projectile consumes more sliding energy compared with the flat projectile.

\section{Soft Projectile}

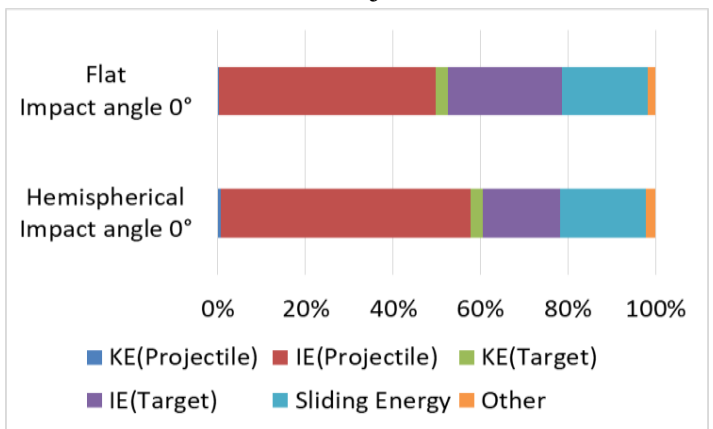

Fig. 34 Energy-contribution ratios for normal impact.
Soft Projectile

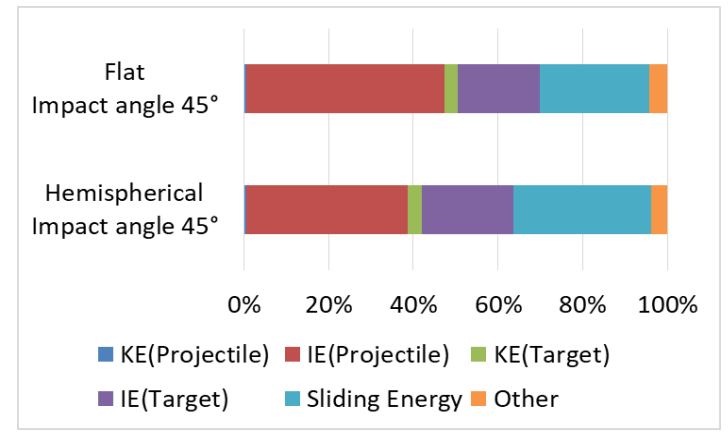

Fig. 35 Energy-contribution ratios for oblique impact.

\section{Conclusion}

In this work, the local damages to RC panel caused by the oblique impacts of rigid and soft projectiles with hemispherical or flat noses were investigated using a validated analytical approach. Results associated with the penetration depth of the RC structure and the energy-contribution ratio were presented. Based on the analytical results, the influence of the nose shape of the projectiles on the local damage caused to RC panel was obtained for normal and oblique impact.

It is found that the local damage on $\mathrm{RC}$ panel caused by rigid projectile with flat nose is approximately 1.5 times greater than that caused by normal impact with hemispherical nose. In the case of oblique impact, the extent of local damage to the RC panel is similar for both types of rigid projectiles. However, a difference was observed with respect to the damage caused by normal impact. A possible reason for this slight difference in local damage to the RC panel due to oblique impact could be the consumed sliding energy.

To clarify the influence of the projectile's nose shape on the impact damage of the RC panel, the local damage of the RC panel subjected to two kinds of soft projectiles with different nose shapes was investigated. In the case of normal impact, the internal energy of the soft projectile expended for damage of the hemispherical nose part is larger than that of the flat nose part because the hemispherical nose part fully buckled. According to these results, the internal energy of the RC panel for the hemispherical projectile decreases. In the case of oblique impact, the internal energy of the soft projectile with hemispherical nose shape is lower than that of the projectile with the flat nose shape. Additionally, the internal energy of the RC panel for the hemispherical projectile slightly increases.

The sliding energy for the oblique impact is higher than that for the normal impact due to the influence of the slip from the nose part. Also, for the two cases of oblique impact, the hemispherical projectile consumes more sliding energy than the flat projectile.

For future work, the numerical achievements should be validated, together with the developed analytical formula for investigating the effect of the nose shape on the local damage of concrete. Based on the validated numerical results, the aim of this study is to propose a new formula for evaluating the local damage to RC structures caused by oblique impacts.

\section{Acknowledgment}

The authors wish to thank the help given by Mr. Minoru NAGAI in analyzing the simulation results of this study. 


\section{References}

Architecture Handbook II - Structure -, 2nd edition, Maruzen, (1977), (in Japanese).

Beth, R. A. and Stipe, J. G., Penetration and explosion test on concrete slabs, (1943).

Haldar, A. and Hamieh, H., Local effect of solid missiles on concrete structures, ASCE Journal of the Structural Division, Vol.110, No.5 (1984), pp.948-60.

Kennedy, R.P., Effects of an aircraft crash into a concrete reactor containment building, Anaheim, CA: Holmes \& Narver Inc. (1966).

Kennedy, R.P., A review of procedures for the analysis and design of concrete structures to resist missile impact effects, Nuclear Engineering and Design, Vol.37 (1976), pp.183-203.

Koshika, N., A study on local damage of concrete structures subjected to impact loads, (1994).

Li, Q.M., Reid, S.R., Wen, H.M. and Telford, A.R., Local impact effects of hard missiles on concrete targets, International Journal of Impact Engineering, Vol.32 (2005), pp.224-284.

National Defense Research Committee, Effects of impact and explosion, Summary Technical Report of Division 2 , vol.1 (1946), Washington, DC.

Nishida, A., Ohta, Y., Tsubota, H. and Yinsheng, L., A study for evaluating local damage to reinforced concrete panels subjected to oblique impact of deformable projectile, Proceeding of Pressure Vessels \& Piping Conference (PVP-2017) (2017), Paper No. PVP2017-66090.

Nishida, A., Minoru, N., Tsubota, H. and Yinsheng, L., Evaluation of local damage to reinforced concrete panels subjected to oblique impact - Simulation analysis for evaluating perforation phenomena caused by oblique impact of deformable projectiles -, Mechanical Engineering Journal, Vol.5, No.5 (2018), DOI: 10.1299/mej.18-00087.

Nishida, A., Zuoyi, K., Minoru, N., Tsubota, H. and Yinsheng, L., Evaluation of local damage to reinforced concrete panels subjected to oblique impact by soft missile, Nuclear Engineering and Design, Vol.350, No.15 (2019), pp.116-127.

OECD/NEA., Improving robustness assessment methodologies for structures impacted by missiles, IRIS_2010 Final report, NEA/CSNI/R (2011).

OECD/NEA., Improving robustness assessment methodologies for structures impacted by missiles, IRIS_2012 Final report, NEA/CSNI/R (2014).

Ohta, Y., Nishida, A. and Tsubota, H., A study for evaluating local damage to reinforced concrete panels subjected to oblique impact, Part 1: a study for evaluating local damage caused by oblique impact of rigid projectiles, Proceedings of the 25th International Conference on Nuclear Engineering ICONE25 (2017), Paper No. ICONE25-66175.

Sugano, T., Tsubota, H., Kasai, Y., Koshika, N., Ohnuma, H., Riesemann, W.A., Bickel, D.C. and Parks, M.B., Local damage to reinforced concrete structures caused by impact of engine missiles, Part 1. Test program, method and results, Nuclear Engineering and Design, Vol.140, No.3 (1993a) pp.387-405.

Sugano, T., Tsubota, H., Kasai, Y., Koshika, N., Itoh, C., Shirai, K., Riesemann, W.A., Bickel, D.C. and Parks, M.B., Local damage to reinforced concrete structures caused by impact of engine missiles, Part 2. Evaluation of test results, Nuclear Engineering and Design, Vol.140, No.3 (1993b) pp.407-423.

Tanaka, N. and Ohno, T., Examine the local damage of concrete plate subjected to hypervelocity oblique impact of small projectile, Proceedings of the 7th Symposium on Impact Problems in Civil Engineering, (2004), pp.147-152.

The Japan Welding Engineering Society (JWES), Method of assessing brittle fracture in steel weldments subjected to large cyclic and dynamic strain, (2003). 